\title{
DE BADAJOZ A BURGOS: JUAN RODRÍGUEZ DE FONSECA EN SUS CATEDRALES
}

\section{FROM BADAJOZ TO BURGOS: JUAN RODRÍGUEZ DE FONSECA IN HIS CATHEDRALS}

\author{
María Dolores Teijeira Pablos \\ Instituto de Estudios Medievales. Universidad de León. España \\ md.teijeira@unileon.es
}

\begin{abstract}
Don Juan Rodríguez de Fonseca fue obispo sucesivamente de Badajoz, Córdoba, Palencia y Burgos, y en su paso por todas estas sedes fue dejando una serie de obras artísticas que muestran tanto un interés por la adecuación de sus catedrales a sus diversas funciones, como un evidente deseo de pervivencia de su propia memoria a través de ellas, sin descuidar su actualización según los modelos artísticos vigentes y una calidad garantizada por el encargo a los artistas más significativos de su época. En este artículo se pretende definir su papel como patrón artístico en relación con las catedrales de las que fue obispo.
\end{abstract}

Palabras clave: Juan Rodríguez de Fonseca; Badajoz, Burgos; patronazgo artístico; catedral.

Don Juan Rodríguez de Fonseca was successively bishop of Badajoz, Córdoba, Palencia and Burgos; in every see he left several works of art in which we can see different aims: the interest in adapting the cathedral building to its functions, the survival of the bishop personal memory on them, the use of the newest artistic models and the highest quality based on the work of the most important artists of his time. This paper focuses on establishing Fonseca's role as an artistic patron in his cathedrals.

Keywords: Juan Rodríguez de Fonseca; Badajoz; Burgos; artistic patronage; cathedral.

\section{INTRODUCCIÓN}

Juan Rodríguez de Fonseca (1451-1524) es sin duda una de las figuras más significativas del panorama artístico de su tiempo, un tiempo tan atractivo como el propio personaje, a caballo -como la época- entre los momentos finales de la 
Edad Media y el principio de la modernidad, entre gótico y renacimiento ${ }^{1}$. Miembro de una de las más importantes familias de la Castilla bajomedieval ${ }^{2}$, y relacionado por lazos de parentesco con otros patronos artísticos tan interesantes como los cuatro Alonso de Fonseca y el cardenal Cervantes ${ }^{3}$, Juan Rodríguez obedece al modelo de prelado culto y con innegables dotes políticas del que los Reyes Católicos procuraron rodearse en su corte.

Como todos los hijos no primogénitos de las grandes familias castellanas tuvo una educación esmerada que debió iniciarse en Salamanca, donde estudiaría Artes, y donde supuestamente adquiriría los conocimientos geográficos necesarios para poder llevar a cabo con eficacia su participación en la organización de los viajes colombinos y la gestión de los asuntos indianos, seguramente su actividad más conocida ${ }^{4}$.

${ }^{1}$ Este texto, que se presentó al Seminario El patronazgo episcopal del último gótico en las catedrales castellanas (Universidad de León, 12 y 13 de noviembre de 2015), se ha elaborado dentro del proyecto "El patronazgo artístico en el reino de Castilla y León (12301500). Obispos y catedrales", Ref. HAR2013-44536-R, financiado por el Ministerio de Economía y Competitividad y fondos FEDER.

2 SAGARRA GAMAZO, Adelaida: Juan Rodríguez Fonseca. Un toresano en dos mundos. Zamora, 2006. Fue hijo de Fernando de Fonseca y Ulloa y de su segunda esposa, Teresa de Ayala y Cervantes.

3 Alonso de Fonseca y Ulloa (Alonso I), denominado el "arzobispo viejo", su tío paterno, fue primero obispo de Ávila y después arzobispo de Sevilla y Santiago. FRANCO SILVA, Alfonso: "El arzobispo de Sevilla Alonso de Fonseca el viejo. Notas sobre su vida", Boletín de la Real Academia de la Historia, CXCVI, 1999, pp. 43-50. Su primo Alonso de Fonseca y Acevedo (Alonso II), denominado el "arzobispo nuevo", lo fue también de Sevilla y Santiago; ambos protagonizaron el conocido intercambio de sedes. VÁZQUEZ BERTOMEU, Mercedes: "El arzobispo don Alonso II de Fonseca. Notas para su estudio", Cuadernos de Estudios Gallegos, XLVII, 112, 2000, pp. 87-131; y OLLERO PINA, José Antonio: "El trueque de sedes de los Fonseca: Sevilla, 1460-1464. Un comentario a Alonso de Palencia", Historia, Instituciones y Documentos, 37, 2010, pp. 211-282. Alonso de Fonseca y Ulloa (Alonso III), hijo del anterior, arzobispo de Santiago y Toledo, tomó posesión del obispado palentino en nombre de su primo Juan. Alonso de Fonseca y Quijada, obispo de Ávila, Osma y Cuenca, como los dos anteriores, era primo de Juan. Juan de Cervantes, obispo de Osma, Ostia, Segovia y arzobispo de Sevilla y cardenal, era tío de su madre y un referente en su vida a pesar de haber coincidido únicamente dos años con él, cuando era un niño. GOÑI GAZTAMBIDE, José: "Cervantes, Juan de", en Diccionario de Historia Eclesiástica de España. Suplemento I. Madrid, 1987, pp. 124-128.

${ }^{4} \mathrm{Su}$ labor al frente de los asuntos americanos, que ocupó una parte importantísima de su vida, ha sido ampliamente estudiada por Adelaida Sagarra. Ver, entre otros, SAGARRA GAMAZO, A.: Juan Rodríguez Fonseca. Un toresano..., op. cit.; SAGARRA GAMAZO, Adelaida: Colón y Fonseca: la otra versión de la historia indiana. Valladolid, 1997; y SAGARRA GAMAZO, Adelaida: "Juan Rodríguez de Fonseca y la fórmula de regionalización americana (1493-1504): estudio de un memorial de 1503", en Isabel la Católica y su época. Valladolid, 2007, pp. 935-949. Sobre sus conocimientos de geografía SAGARRA 
Desde muy pronto -al menos entre 1470 y 1473-debió estar al cargo de su tío Alonso de Fonseca, el llamado "arzobispo viejo", que lo era entonces de Sevilla; hombre de gran talento, sobre todo como político, de él debió de aprender no pocas habilidades en este campo ${ }^{5}$. Su tío, hombre de gran cultura, se preocupó de su educación, trayendo de Italia a Antonio de Nebrija con este fin ${ }^{6}$, y favoreciendo quizá su vuelta a la Universidad salmantina, donde Fonseca se presentó a una cátedra en 1471, aunque no la consiguió ${ }^{7}$.

Que la religión no era su vocación y que nunca debió sentir gran interés por los asuntos espirituales lo prueba el hecho de que se ordenara muy tardíamente, en $1493^{\circ}$, con 42 años y habiendo sido ya arcediano de Oropesa, Olmedo, Ávila y Sevilla, seguramente también deán de esta última sede, y desde 1484 capellán real ${ }^{9}$. En su elección de la carrera eclesiástica debió influir la necesidad de

GAMAZO, Adelaida: "Elio Antonio de Nebrija y Juan Rodríguez de Fonseca: de la gramática a la cartografía al servicio de la reina", Revista de Estudios colombinos, 2, 2006, pp. 29-40.

5 Tanto el arzobispo viejo como los otros tres alonsos fueron destacados patronos artísticos. El primero hizo importantes donaciones al monasterio de la Mejorada de Olmedo, entre ellas el conocido retablo de San Jerónimo, de Jorge Inglés. ARIAS MARTÍNEZ, Manuel: "Sobre el retablo de San Jerónimo del pintor Jorge Inglés", Boletín del Museo Nacional de Escultura, 1, 1996-1997, pp. 7-14; y ARIAS MARTÍNEZ, Manuel: "Retablo de San Jerónimo", en Pintura del Museo Nacional de Escultura. Siglos XV al XVIII. Madrid, 2001, pp. 40-41. Alonso II y III vincularon su patronazgo a sus sedes, especialmente a la catedral de Santiago, donde el arzobispo joven legó un millón de maravedís para el claustro a su muerte, y a la ciudad de Salamanca, donde el padre fundó el convento de la Anunciación, que continuaría su hijo y donde éste fundaría el colegio Fonseca, como ya había hecho con su homónimo santiagués. CASTRO SANTAMARÍA, Ana: El Colegio mayor del arzobispo Fonseca o de los Irlandeses. Salamanca, 2003; y GARCÍA IGLESIAS, José Manuel: Fonseca: patrimonio e herdanza. Arquitectura e iconografía dos edificios universitarios composteláns (ss. XVI-XX). Santiago de Compostela, 2000.

${ }^{6}$ De Nebrija pudo obtener también sus conocimientos geográficos, fundamentales para su importantísima intervención en los asuntos americanos. SAGARRA GAMAZO, A.: "Elio Antonio de Nebrija y Juan Rodríguez de Fonseca...", op. cit.

${ }^{7}$ Lo hizo en su lugar Diego Ramírez de Villaescusa, un obispo con un perfil muy semejante al suyo.

${ }^{8}$ FITA COLOMÉ, Fidel: "Órdenes sagradas de don Juan Rodríguez de Fonseca, arcediano de Sevilla y de Ávila, en 1493”, Boletín de la Real Academia de la Historia, 20, 1982, p. 178. El 2 de marzo de dicho año fue ordenado subdiácono en la capilla de San Bartolomé de la catedral de Barcelona y el 6 de abril recibió el presbiterado. En el Liber ordinatorum, de donde se toma este dato, se le identifica como arcediano de Sevilla y Ávila y capellán de la reina.

${ }_{9}$ Sus sucesivos obispados supondrían el reconocimiento de los reyes a sus buenos servicios políticos. El de Palencia sería una recompensa de la reina por sus servicios en Flandes; el de Burgos, según Sagarra, podría ser un pago por los préstamos que los mercaderes burgaleses habían hecho al rey Fernando en 1512 para los asuntos americanos. 
labrarse una carrera propia, pero también quizá, además del ejemplo de su tío el arzobispo, el no menos importante de fray Hernando de Talavera ${ }^{10}$, a quien debió conocer en la corte y quien le protegió a partir sobre todo de la década de los 80. De él aprendería las habilidades políticas, diplomáticas y de gestión que después aplicaría en sus misiones europeas y americanas, aunque no parece haberle influido el ideal de vida austera y sencilla, de fuerte inspiración cristiana, de Talavera, a quien la reina se lo encomendó para que "aprendiese a ser santo" y con quien pasó a Granada, parece que como provisor, al ser éste nombrado primer arzobispo tras la conquista ${ }^{11}$.

En la década de los 90 comenzó su carrera episcopal, al ser nombrado obispo de Badajoz en 1495. De Badajoz pasó a Córdoba en 1499, a Palencia en 1504 y a Burgos en 1514, cargo este último que mantendría hasta su muerte en 1524, al igual que el de arzobispo de Rosano, al que había accedido en 1511, aunque hasta 1513 no tomaría posesión del mismo. También mantuvo hasta su muerte el cargo de abad en encomienda de San Zoilo de Carrión desde antes de 1515, y San Isidoro de León desde 1519, y seguramente también el de Santa María de Párraces, aunque en este caso las fechas son muy inciertas ${ }^{12}$.

A partir de los años 90, ya como religioso y agente político de los Reyes Católicos, comenzó a interesarse por las cuestiones artísticas, aspecto en el que también debió influir el ejemplo de su tío el arzobispo, hombre amante del lujo y la belleza ${ }^{13}$, como el propio Juan Rodríguez ${ }^{14}$. En este campo la actividad y los

SAGARRA GAMAZO, Adelaida: "La reina Juana y don Juan de Fonseca: ¿una hoja de servicios con precio político?”, Revista de Estudios Colombinos, 6, 2010, pp. 13-23.

${ }^{10}$ LADERO QUESADA, Miguel Ángel: "Fray Hernando de Talavera en 1492: de la corte a la misión", Chronica Nova, 34, 2008, pp. 249-275.

11 TERESA LEÓN, Tomás: "El obispo don Juan Rodríguez de Fonseca: diplomático, mecenas y ministro de Indias", Hispania Sacra, 1960, p. 254.

${ }_{12}$ A fines de 1515, en un documento de la catedral de Burgos, se le identifica como administrador perpetuo de las abadías de Párraces y de San Zoilo de Carrión. Archivo Capitular de Burgos (A.C.B.), lib. 46, f. 394r, 4-12-1515.

${ }^{13}$ Hernando del Pulgar destacó el gusto del arzobispo viejo por las cosas bellas, más allá de la simple ostentación, lo que lo situaría en la vía del coleccionista moderno. CHECA, Fernando: "Poder y piedad: patronos y mecenas en la introducción del Renacimiento en España", en Reyes y Mecenas. Los Reyes Católicos-Maximiliano I y los inicios de la casa de Austria en España. Toledo, 1992, p. 25.

${ }^{14}$ Como estudios generales de su faceta como promotor artístico puede consultarse YARZA LUACES, Joaquín: "Dos mentalidades, dos actitudes ante las formas artísticas: Diego de Deza y Juan Rodríguez de Fonseca (1500-1514)", en Jornadas sobre la catedral de Palencia. Valladolid, 1989, pp. 105-142; REDONDO CANTERA, María José: "Juan Rodríguez de Fonseca y las artes", en SAGARRA GAMAZO, Adelaida (ed.): Juan Rodríguez de Fonseca: su imagen y su obra. Valladolid, 2005, pp. 175-206; y PAYO HERNANZ, René Jesús y MATESANZ DEL BARRIO, José: La Edad de Oro de la Caput Castellae. Arte y sociedad en Burgos. 1450-1600. Burgos, 2015, pp. 453-462. 
intereses de Fonseca, aparte de las habituales donaciones en metálico ${ }^{15}$, se centraron sobre todo en garantizar que los templos bajo su responsabilidad cumplieran su función litúrgica de la manera más correcta y más adecuada a su tipología y jerarquía, lo que podría resumirse en dos términos que aparecen habitualmente en la documentación relacionada con su actuación: ornato -en el sentido de monumentalidad, suntuosidad y riqueza- y dignidad -en el sentido de adecuación a la función, importancia y categoría de cada obra $-^{16}$. A estos habría que añadir memoria, en cuanto que las obras emprendidas mantuviesen vivo el recuerdo de su patrón, su linaje y la importancia de su cargo.

Además de estos principios, extensibles a un número importante de prelados que actuaron como importantes patronos artísticos en esta época, puede detectarse en Juan Rodríguez de Fonseca una implicación más personal en las obras de arte que encargó, todas ellas complejas, de altísima calidad artística y realizadas en función de objetivos muy específicos, además de obedecer a un determinado modelo artístico, aspecto este último en el que puede verse una clara evolución a lo largo de su vida.

\section{LA PROMOCIÓN ARQUITECTÓNICA}

En su carrera eclesiástica, siempre ascendente, pasó por diversas catedrales castellanas en momentos en los que los templos estaban en construcción, remodelación o transformación espacial de algún tipo, lo que le permitió intervenir en

${ }^{15}$ Conocemos sobre todo las establecidas en su testamento, en el que dejó diversos legados a otras casas religiosas cuya relación con el obispo no siempre es fácil de establecer, aunque el hecho de que la mayoría se encontrase en Burgos -convento de Santa Dorotea, monasterios del Moral, Ausín y palacios de Benagel- parece señalar unas relaciones establecidas en sus últimos años de vida. El testamento de Juan Rodríguez de Fonseca se conserva, en copia contemporánea, en el Archivo Ducal de Alba, sección de Patronato, A.A.c.342-1/7 - citado a partir de ahora como Testamento y el número de la cláusula-, a cuyo director, don José Manuel Calderón, quiero agradecer su amabilidad y eficacia al haberme proporcionado copia de dicho documento.

${ }^{16}$ La preocupación por el ornato y dignidad de los espacios del templo se mencionan expresamente en el permiso otorgado por el obispo, en 1519, al canónigo burgalés Gonzalo Díez de Lerma para construir su capilla funeraria en la capilla de la Presentación o Consolación de la catedral: "que el dicho lugar es honesto y conducente para dicha capilla, la cual edificada acrescentará ornato y autoridad a la dicha nuestra santa iglesia, aunque el edificio della parece al presente que será de algún perjuicio para los dichos palacios episcopales". MANSILLA, Demetrio: "Capilla de la Presentación de Nuestra Señora en la catedral de Burgos. Datos para su historia", Boletín de la Institución Fernán González, 144, 1958, p. 257. 
la resolución de problemas arquitectónicos de diferente índole en cada caso ${ }^{17}$. Es probable que en algunos casos simplemente tuviese que ofrecer una solución a un problema concreto, pero desde luego en otros está clara su voluntad de crear nuevos espacios a partir de fórmulas que le dieran un importante protagonismo dentro del templo, lo que, con la adición de su propia imagen, bien a través de su retrato, bien a través de sus armas, redundaría en su propio beneficio y el del cargo episcopal, en el marco de las complejas relaciones entre obispos y cabildos. Este interés parece apreciarse también en su probable implicación en la construcción de edificios, especialmente religiosos, en el Nuevo Mundo, donde la adecuación de la edificación fue una preocupación importante y donde es posible detectar la presencia de arquitectos cercanos a Fonseca, en los años en los que el se encontraba al frente de los asuntos americanos ${ }^{18}$.

De todas las sedes que ocupó fue sin duda la palentina (1504-1514) con la que tuvo una relación más estrecha, aunque no fue en la que estuvo más tiempo. Además de que sí hay constancia de su presencia en la sede, cosa que no puede decirse de las dos anteriores, el interés puesto en su templo va más allá de la aportación

${ }^{17}$ En Sevilla vivió los últimos años de completamiento de la fábrica. RODRÍGUEZ ESTÉVEZ, Juan Clemente: "Cambio y continuidad en el proyecto gótico de la catedral de Sevilla", Laboratorio de Arte, 23, 2011, pp. 33-64; y JIMÉNEZ MARTÍN, Alfonso (coord.): La catedral gótica de Sevilla: fundación y fábrica de la "obra nueva”. Sevilla, 2007. En la catedral de Badajoz quedaba todavía por terminar la catedral gótica que sustituiría a la obispal, acondicionada en la antigua mezquita. A fines del XIV el cabildo había vuelto a utilizar esta debido a las guerras con Portugal, permaneciendo en ella hasta fines del siglo XV, dado que era más segura al encontrarse en la parte alta de la ciudad. MOGOLLÓN CANO-CORTÉS, Pilar: "La iglesia de Santa María la Obispal de Badajoz, símbolo de la arquitectura de control en poblaciones multiculturales", De Arte, 1, 2002, pp. 41-54. Se desconoce la intervención del obispo en este tema, aunque parece que no estuvo nunca en la sede, por lo que no conocería, al menos de primera mano, los problemas del edificio, sin dejar de ser sensible a sus necesidades inmediatas. Algo similar debió suceder en Córdoba, sede en la que probablemente tampoco estuvo nunca, pero cuya catedral tenía pendiente el acondicionamiento de la mezquita para su uso religioso cristiano, en cuyo sentido ya algún obispo previo había iniciado obras que culminarán con la construcción del crucero en el primer cuarto del siglo XVI. MORENO CUADRO, Fernando: "El crucero de la catedral de Córdoba. Estudio iconográfico e iconológico", Cuadernos de arte e iconografía, 31, 2007, pp. 12-ss. En Palencia se encontró también con un edificio en construcción y en Burgos con uno ya terminado pero con algunos problemas espaciales que solucionar, como se verá.

18 ALONSO RUIZ, Begoña: “'Mezclar el mundo'. Los primeros constructores castellanos en el Caribe”, en SAZATORNIL RUIZ, Luis (ed.): Arte y mecenazgo indiano: del Cantábrico al Caribe. Gijón, 2007, pp. 89-104. 
económica o la donación de obras, suponiendo una mayor implicación en la configuración del templo catedralicio, aún en construcción en esos años ${ }^{19}$.

Además de completar la iglesia, ampliando en un tramo su cuerpo, lo que supondría un aumento considerable en el tamaño del edificio ${ }^{20}$, Fonseca patrocinó otras importantes obras arquitectónicas, necesarias dentro del conjunto, como la sala capitular (Figura 1) y el claustro, que habría contratado con Juan Gil de Hontañón en 1505, antes incluso de haber tomado posesión de la sede ${ }^{21}$. Estas últimas obras, como las reparaciones que debió promover en la puerta del obispo (Figura 2), formaban parte de la conservación y adecuación del edificio y demuestran la generosidad de Fonseca y su deseo de cumplir con su misión de dotar a su diócesis de una catedral que pudiera desempeñar correctamente su función como primer templo de la diócesis, a la vez que le permitió dejar huella de su paso por la sede a través de sus escudos, familiar y personal.

Sin embargo, la también temprana decisión de abordar la finalización del templo aumentando su tamaño va más allá de los habituales deberes del obispo y muestra un interés artístico mayor al mejorar las proporciones del edificio y al aprovechar el problema que planteaba el cuerpo de la iglesia con respecto a la cabecera del templo para dar una solución que le permitiera a la vez modificar la imagen simbólica del mismo y poner de manifiesto el protagonismo del obispo en la obra, a través, entre otros, de sus armas en la claves polares de las bóvedas del coro (Figura 3).

19 Sobre la situación de la catedral palentina al tomar posesión Juan Rodríguez de Fonseca del obispado, HERRÁEZ ORTEGA, María Victoria: "Los prelados palentinos y el proceso constructivo de la catedral de San Antolín a lo largo del siglo XV", presentado en el Seminario citado en nota 1.

${ }^{20}$ Sobre la catedral de Palencia ver MARTÍNEZ GONZÁLEZ, Rafael: La Catedral de Palencia. Historia y Arquitectura. Palencia, 1988. La obra se completaría ya en 1516, siendo obispo de Burgos, aunque ello no supuso que se desentendiera de lo comenzado en Palencia; muy al contrario siguió ayudando económicamente a la obra, además de mantener otros lazos con la ciudad, donde era comisario de cruzada. De hecho, en 1513, cuando se establece por parte del obispo la obligación de crear un altar en el trascoro, el mismo dice que "si place a Nuestro Señor que dexemos la posesión de Nuestra Santa Yglesia de Palencia, tenemos voluntad de acabar el trascoro que hacemos la dicha memoria". Documento transcrito en WATTENBERG GARCÍA, Eloísa: "El trascoro de la catedral de Palencia", Boletín del Seminario de Arte y Arqueología, XI, 1944-1945, p. 183. María José Redondo ve además huellas de una posible intervención del burgalés Francisco de Colonia en el nuevo coro palentino, lo que reforzaría este interés del obispo por esta obra, ya desde la sede de Burgos. REDONDO CANTERA, M. J.: "Juan Rodríguez...", op. cit., pp. 184-185.

${ }^{21}$ GARCÍA CUESTA, Timoteo: "La catedral de Palencia según los protocolos", Boletín del Seminario de Arte y Arqueología, 1955, pp. 67-90; y REDONDO CANTERA, M. J.: "Juan Rodríguez...", op. cit., p. 179. 
Es lo que sucede con el traslado de la capilla mayor, coro incluido, la modificación de este y del retablo mayor -que se ampliaría con las pinturas que contrató en 1509 con Juan de Flandes-, la construcción del trascoro y los cerramientos laterales del coro y de la escalera de bajada a la cripta de San Antolín ${ }^{22}$. Este conjunto de obras creó un ámbito espacial nuevo en torno a la zona del coro, a partir de ahora en la nave central, espacio que vincula de una manera más clara los lugares centrales de la catedral -altar mayor y coro- con la cripta y, por lo tanto, con el origen legendario del templo y su antigüedad (Figura 4). Esto aumentaría el prestigio de la sede, dando al obispo Fonseca un protagonismo fundamental dentro de su templo, al presidir permanentemente este nuevo espacio su propia imagen -desde el retablo que para el trascoro encargaría en Flandes- y perpetuarse su presencia, además, gracias al establecimiento de una liturgia propia en el rezo sabatino de la $\mathrm{Salve}^{23}$. La probable disposición de los tapices por él regalados a la catedral en los intercolumnios de las naves laterales completaría la configuración de un nuevo centro de atención dentro del templo, a mayor gloria de la memoria del obispo, presente por todas partes gracias a la multiplicación de sus escudos $^{24}$.

En esta zona del trascoro se creó así, todos los sábados desde la muerte del obispo, un espacio autónomo, efímero, en el que Juan Rodríguez de Fonseca volvía a presidir el coro por medio de su retrato "sacado del natural bien propiamente" en la tabla central del retablo del trascoro (Figura 5) ${ }^{25}$, en una paraliturgia

${ }^{22}$ REDONDO CANTERA, M. J.: "Juan Rodríguez...”, op. cit.; y ALONSO RUIZ, Begoña: "El coro y el trascoro de la Catedral de Palencia. Arquitectos y entalladores del tardogótico", en Choir stalls in architecture and architecture in choir stalls. Cambridge, 2015, pp. 234-249.

${ }^{23}$ GRANADOS SALINAS, Rosario Inés: "Sorrows for a devout ambassador. A Netherlandish Altarpiece in sixteenth century Castile", Potestas, 1, 2008, pp. 101-130; YARZA LUACES, J.: "Dos mentalidades...”, op. cit.; y HOYOS ALONSO, Julián: “Juan Rodríguez de Fonseca y el trascoro de la catedral de Palencia, un espacio simbólico", en LOMBA, Concha; LOZANO, Juan Carlos; ARCE, Ernesto y CASTÁN, Alberto (coords.): El recurso a lo simbólico. Reflexiones sobre el gusto, II. Zaragoza, 2014, pp. 223-233.

${ }^{24}$ Estos se muestran individualizados o en parejas, en diferentes combinaciones: escudo familiar y personal del obispo, escudo del obispo y de los Reyes Católicos, escudo del obispo y del cabildo. Se establecen de este modo diferentes relaciones centradas en los intereses de Fonseca: linaje, servicio y cercanía a la corona y presencia episcopal en la sede.

${ }^{25}$ Juan Rodríguez de Fonseca aparece en esta tabla vestido como un clérigo. Asistiría a coro en estas fechas con sobrepelliz sobre las pieles que le protegerían del frío palentino, sin capa ni mitra -ésta en el suelo-propias de la suntuosidad del pontifical que sí utilizó en otras obras. Con respecto a la identificación de estos y otros ornamentos quiero expresar mi más profundo agradecimiento al Dr. Pablo Pomar por haber aclarado mis dudas con su amplísima erudición en cuestiones litúrgicas. Sobre el uso de pieles bajo la ropa de coro, costumbre que debía ser habitual en el hábito de invierno, ver la carta que el obispo de Valencia, Isidoro Aliaga, envía al de Barbastro en 1617, publicada en VILLANUEVA, Jaime: 
diseñada cuidadosamente por el propio obispo ${ }^{26}$, y que constaba de una misa cantada y el rezo de la salve, cuyo texto se incluía en los tapices que, con esta temática, cerraban el espacio, por los beneficiados "vestidos con sus sobrepellices, hechos dos coros de rodillas delante de nuestra señora", en torno a la escalera de bajada a la cripta de San Antolín que el mismo Fonseca había mandado trasladar desde su ubicación anterior. Al beneficio espiritual que recibiría su alma se unía, evidentemente, la permanencia de la memoria del obispo en la catedral con la que tuvo una relación más estrecha y a la que seguiría favoreciendo con su patronazgo hasta el momento de su muerte, incluso en su testamento ${ }^{27}$, sin olvidar el reforzamiento que para la figura del prelado suponía su presencia permanente en el ámbito coral, renovando semanalmente la imagen de su preeminencia sobre los canónigos en su propio edificio.

Desde 1514 hasta su muerte en 1524 fue obispo de Burgos, ciudad donde tuvo numerosos problemas con el cabildo por diversas cuestiones, sobre todo de jurisdicción, pero en la que debió residir con bastante frecuencia y de la que sería obispo hasta su muerte ${ }^{28}$.

La primera obra que planteó en la catedral burgalesa fue la intervención en el acceso al templo por la portada de la Coronería. En 1516 mandó, contra la opinión del cabildo, cerrar dicha puerta y derribar la escalera por la que se accedía a la catedral desde la parte alta de la ciudad ${ }^{29}$. La "puerta alta" fue tradicionalmente problemática, debido al frío que entraba por ella y a que los burgaleses aprovechaban dicho acceso no solo para entrar en el templo, sino sobre todo para llegar a la parte baja de la ciudad sin tener que rodearlo; de este modo habría un continuo trasiego de personas y animales que cruzarían todo el transepto de la catedral para poder salir por la puerta del Sarmental, lo que evidentemente supondría un trastorno importante en las celebraciones litúrgicas que tenían lugar en el coro,

Viaje literario a las iglesias de España. Vol. II. Madrid, 1840, p. 229. Quiero agradecer a la Dra. Teresa Laguna el haber llamado mi atención sobre este documento.

${ }^{26}$ De la importancia que daba Fonseca a la correcta realización de este ritual, que se mantuvo hasta 1990, da una idea el detalle con que aparece descrito en la documentación conservada y en la queja que su hermano Antonio envió al cabildo, en 1530, por la deficiente realización del mismo. HOYOS ALONSO, J.: "Juan Rodríguez...”, op. cit., p. 225.

${ }^{27}$ En la cláusula 32 del testamento establece que se compre un juro "para la memoria que nos tenemos mandada hacer en la iglesia de Palencia”.

${ }^{28}$ Parece que en 1524, año de su muerte, habría rechazado, por razones económicas, el arzobispado de Santiago, que le habría gestionado el emperador. RODRÍGUEZ VILLA, Antonio: "El Emperador Carlos V y su corte. (1522-1539). I. Cartas de D. Martín de Salinas (2)", Boletín de la Real Academia de la Historia, XLIII, 1903, p. 152.

${ }_{29}$ SPERANZA, Fabio: "La escalera dorada de la catedral de Burgos", Archivo Español de Arte, 293, 2001, p. 19, citando a MARTÍNEZ SANZ, Manuel: Historia del templo catedral de Burgos, escrita con arreglo a documentos de su archivo. Burgos, 1866 (ed. Burgos, 1997), p. 125; y LÓPEZ MATA, Teófilo: La catedral de Burgos. Burgos, 1950, p. 284. 
entonces en la capilla mayor, además de una evidente falta de la dignidad o autoridad tan importantes para el obispo ${ }^{30}$. Además, es posible que en estas fechas no se encontrara en muy buen estado de conservación, ya que había resultado dañada, en su parte baja, por las obras de la cercana capilla de la Concepción, que había acondicionado años antes el obispo Luis de Acuña como capilla funeraria propia $^{31}$.

Para mantener el acceso desde la parte alta y la cabecera de la catedral encargó en el mismo año de 1516, a Francisco de Colonia, la creación de la puerta de la Pellejería, en el lado oriental del transepto norte, aprovechando una pequeña puerta que daba a un corral que había en esa zona ${ }^{32}$ (Figura 6). Para monumentalizar este acceso encargó una portada en varios cuerpos, rematada por su propia efigie, revestido de medio pontifical, orante ante la Virgen con el Niño acompañada de tres ángeles músicos (Figura 7) y por su escudo (Figura 8). La portada, terminada tras la muerte de Fonseca, muestra ya el conocimiento de las formas renacentistas, si bien de una manera aún superficial y más de ornato que de concepto ${ }^{33}$.

En 1519 "propuso sobre que quería tornar a facer la escalera en la puerta alta de la correría donde solía, la cual el había mandado quitar, et que agora la quería facer conforme a una traza que mostró en el dicho cabildo Diego de Sylue imaginario, en presencia de S.S. e de los dichos señores"34; la escalera dorada se acabaría en 1522, y su antepecho de rejería ya tras la muerte de Fonseca, en 1526, y si bien fue encargo suyo la escasez de su heráldica y los pagos del obrero de la fábrica podrían

${ }^{30}$ Ello a pesar de que la puerta no debía estar siempre abierta. Así, en 1466 el cabildo mandó a los sacristanes que abrieran esta puerta, entre otras, durante los maitines. A.C.B., Libro Registro 17, f. 414v, 22-8-1466. En 1473 ordenó a los campaneros que los días que hiciera bueno abrieran las puertas del Sarmental, de la Coronería, de la Pila y la de las Trojes y los domingos y días de fiesta y procesiones, la puerta Real. Libro Registro 18, f. 477r, 5-3-1473. Según Martínez Sanz, se cerró definitivamente hacia 1786, abriéndose solo en invierno cuando el hielo hacía peligroso bajar por la calle, y solo para los oficios, hasta 1830 , cuando se cerró definitivamente. MARTÍNEZ SANZ, M.: Historia del templo..., op. cit., pp. 26-27.

${ }^{31}$ En 1485 se dice que Fernando Díez de Fuentepelayo, arcediano de Burgos, estaba tirando parte de esta escalera para edificar la sacristía de esta capilla, espacio que podría aprovecharse para algún enterramiento importante. A.C.B., Libro Registro 22, f. 223r, $23-$ 4-1485.

${ }^{32}$ PAYO HERNANZ, R. J. y MATESANZ DEL BARRIO, J.: La edad de oro..., op. cit., pp. 457-458.

${ }_{33}$ REDONDO CANTERA, M. J.: “Juan Rodríguez...”, op. cit. El conocimiento del modelo renacentista se muestra también en el cambio del escudo, que adopta ahora la tradición italiana al utilizar el tipo "cabeza de caballo".

${ }^{34}$ MARTÍNEZ SANZ, M.: Historia del templo..., op. cit., p. 126. El 4 de noviembre de 1519 expuso su opinión en cabildo sobre dicha traza. A.C.B., Libro Registro 37, f. 186v. 
indicar que se hizo cargo de la obra más el cabildo que el propio obispo ${ }^{35}$. En cualquier caso, la elección de Diego Siloe y la asunción ya clara del modelo renacentista, muestran sin duda una clara evolución en el gusto del obispo, que también se manifestará en otras obras encargadas por él en estos años.

Además de esta obra, y quizá en relación indirecta con ella, intentó infructuosamente modificar la ubicación del coro catedralicio, como ya había hecho en Palencia, planteando un traslado de la capilla mayor a la nave, quizá con un objetivo similar. Fue este un intento tardío en su episcopado, iniciado en 1521, año complicado para el obispo, ya que, tras su participación, en ayuda de su hermano Antonio, en el incendio de Medina del Campo, en agosto de 1520, el obispo tuvo que huir de Burgos y refugiarse en Astorga en los últimos meses de 1520 y primeros de $1521^{36}$. Fue a su vuelta a Burgos cuando planteó el cambio de ubicación del conjunto coral ${ }^{37}$.

En junio de ese año el cabildo burgalés acordó que el deán y otros diputados hablaran con el obispo sobre el cambio del coro que el obispo pretendía y con el que el cabildo no estaba de acuerdo; este prefería hacer modificaciones más pequeñas en la disposición del mobiliario, sin variar su ubicación, además de completar las obras de acondicionamiento que había iniciado el obispo anterior con el encargo de la nueva sillería a Felipe Vigarny y Andrés de Nájera y con un

${ }^{35}$ Así lo cree REDONDO CANTERA, M. J.: "Juan Rodríguez...”, op. cit., p. 202; y SPERANZA, Fabio: "La Escalera...", op. cit. El 31 de enero de 1520 Maestre Hilario reconocía haber recibido, del obrero de la fábrica Diego Gil y del canónigo Gaspar de Illescas, 1.100 ducados de oro por la reja, de la que dice haberla hecho por mandado del obispo. A.C.B., Libro Registro 39, f. 63r.

36 Juan Rodríguez de Fonseca huyó de Burgos, sin encontrar cobijo hasta llegar a Astorga, donde fue acogido por el marqués. Allí se encontraba ya en octubre de 1520, cuando se leyó en el cabildo de Burgos una carta del obispo en la que pedía que se hablara con los procuradores de la ciudad para excusarle de la culpa que se le atribuía en el incendio de Medina. A.C.B., Libro Registro 41, f. 54r. Su huida la cuenta él mismo en una carta dirigida al emperador en enero de 1521, que recogen DANVILA COLLADO, Manuel: Historia crítica y documentada de las comunidades de Castilla. T. III. Madrid, 1897, pp.134-136; y SALVÁ, Anselmo: Burgos en las comunidades de Castilla. Burgos, 1895, cap. XIV.

${ }^{37}$ En octubre de 1520 una delegación del cabildo burgalés, encabezada por Bartolomé de Sedano, fue a Astorga a visitar al obispo. A.C.B., Libro Registro 41, f. 51r. A principios de 1521 el cabildo pidió a Fonseca que volviera, ya que la ciudad ya estaba en paz. A.C.B., Libro Registro 41, f. 63v. Pero a mediados de marzo todavía no había vuelto ni parecía que fuera a volver en breve, ya que en cabildo se discutió si permitir o no la entrada en cabildo de un representante del obispo mientras este no estuviera. A.C.B., Libro Registro 39, f. 171r. A su vuelta debió centrarse más en sus tareas episcopales, ya que había sido alejado de la corte por la influencia de Adriano de Utrecht, a quien, convertido ya en papa, fue Fonseca a besar los pies a principios de 1522, con algunos canónigos, estando aquél en Vitoria. A.C.B., Libro Registro 41, f. 126r. Desde principios de 1523 se vuelve a tener noticias de problemas y pleitos con el cabildo por cuestiones de jurisdicción. 
antecoro, ya comenzado, cuya construcción posiblemente Fonseca hubiera mandado paralizar, ya que el cabildo acordó también su finalización ${ }^{38}$. Es probable que el obispo no se rindiese ante la resistencia capitular a acatar sus deseos y siguiese insistiendo en los meses siguientes, ya que a fines de 1521 el cabildo acordó de nuevo "que la obra del antecoro que estaba comenzado estaba parado porque el (obispo) quería mudar dicho coro y el cabildo no era de ese parescer y estaban determinados a que no se mudase, y que tuviera a bien que la obra continuase y se acabase, y que no había necesidad de hacer la reja del coro que había mandado hacer" 39 . Finalmente el cabildo impuso su opinión y el coro se mantuvo, de momento, en su ubicación original ${ }^{40}$, sin que conozcamos las razones por las que el obispo, poco dado a no imponer su opinión, cedió ante un cabildo que en estos años, de continuos cambios en el espacio coral, dejó clara su intención de no contar con opiniones ajenas en lo que consideraban una competencia exclusiva suya $^{41}$.

Además de la construcción y reforma de los templos Fonseca se preocupó también por otros conjuntos arquitectónicos ligados a sus sedes. Así en Burgos debió promover también obras en el palacio episcopal, en el siempre conflictivo pontido, que mandó reconstruir en varias ocasiones como muestra visible de su preeminencia sobre el cabildo en el gobierno de la diócesis y su protagonismo en el templo ${ }^{42}$. También en Córdoba debió promover alguna obra en el palacio

${ }^{38}$ A.C.B., lib. 32, f. 80v, 14-6-1521. Martínez Burgos transcribe el texto del acta del siguiente modo: "Este día los dichos sennores fablaron sobre quel señor Obispo tiene voluntad de mudar el Coro. Y fablado sobre ello largamente, a los dichos sennores les paresçió que no se debía de mudar, e deputaron al señor Deán, con las personas que a él le paresçiere del Cabildo, para que vayan a su Sennoría a dezirle la voluntad del Cabildo, y sobre que se dé orden que se acabe la obra del antecoro començada". MARTÍNEZ BURGOS, Matías: "En torno a la catedral de Burgos. I. El coro y sus andanzas", Boletín de la Institución Fernán González, 123, 1953, p. 537.

39 A.C.B., Libro Registro 41, f. 109v, 22-11-1521.

${ }^{40}$ En 1528, muerto ya Fonseca, el notario apostólico Fernando de Espinosa describió el espacio coral, todavía en la capilla mayor, poniendo de manifiesto los problemas que generaba el coro en esta ubicación y que quizá fueran los mismos que habían llevado al obispo a plantear el traslado. MARTÍNEZ BURGOS, M.: "En torno a la catedral...", op. cit., pp. 538-539.

${ }^{41}$ Ibidem.

${ }^{42}$ Los problemas entre obispo y cabildo por el pontido - puente volado sobre la escalera del Sarmental que ponía en comunicación el palacio episcopal y el claustro alto de la catedral y que el cabildo siempre vio como una intromisión en sus derechos jurisdiccionales por parte de los obispos- no eran nuevos, de hecho ya se habían planteado, con un pleito, antes de la toma de posesión de Fonseca de la sede y tenían su origen en los que en su día había tenido el cabildo con el obispo Luis de Acuña. Al respecto pueden consultarse varios documentos del archivo capitular de Burgos, como el lib. 46. Sobre la obra del pontido ver PAMPLIEGA PAMPLIEGA, Rafael: Pontido y otras dependencias de la catedral 
episcopal, hoy arruinado, pero donde puede verse todavía un escudo suyo, compañero de otro perdido hace no muchos años ${ }^{43}$. Igualmente favoreció a los hospitales de sus últimas sedes, especialmente al hospital de San Bernabé y San Antolín de Palencia, con reparaciones que el arcediano de Alcor incluye en su Silva Palentina, aunque no da detalles ${ }^{44}$. También al Hospital del emperador de Burgos, al que legó doscientos mil maravedís para terminar la obra ${ }^{45}$.

\section{LA PROMOCIÓN SUNTUARIA}

Junto con la adecuación espacial de los templos, Juan Rodríguez de Fonseca tuvo también muy en cuenta el necesario complemento suntuario, que enfatizase el ornato y dignidad requeridos por los espacios templarios que focalizaban la actividad litúrgica, sin olvidar evidentemente el mantenimiento de su memoria. De este modo regaló, tanto en vida como a su muerte, en forma de legado testamentario, todo tipo de objetos suntuarios a los templos de los que fue responsable, algo bastante habitual en el patronazgo episcopal del momento, toda vez que formaba parte de las obligaciones habituales del obispo el velar por el correcto funcionamiento de la actividad litúrgica en su sede, y por lo tanto debía también asegurar que contase con los objetos necesarios para su desarrollo. A esto se le puede añadir su generosidad y el gusto por el lujo que hemos visto también en sus intereses arquitectónicos. El resultado es un número muy importante de donaciones de orfebrería, libros de coro, ornamentos litúrgicos, tapices y pintura a aquellos templos en los que tuvo un papel rector y que se vieron de este modo embellecidos y solemnizada su actividad litúrgica, a la vez que se hizo más permanente la presencia del propio obispo, a través de sus armas nobiliarias, que no dejaron de tener un lugar protagonista en todas estas obras.

La primera obra de cuya donación tenemos constancia es la pintura de la Virgen de la Antigua que regaló en 1498 a la catedral de Badajoz, de la que entonces

de Burgos. Burgos, 2005, pp. 45-49, que recoge las diversas reconstrucciones del mismo en tiempos de Fonseca: 1514, al tomar posesión de la sede, y 1516, tras su derribo. En cualquier caso, parece que don Juan nunca pudo utilizarlo, al mandar el cabildo construir una pared en la salida al claustro para evitar su uso como pasaje.

${ }^{43}$ GARIJO PÉREZ, Ignacio: "Don Juan Rodríguez de Fonseca, obispo de Córdoba. Un olvidado rastro heráldico", Boletín de la Real Academia de Córdoba, 129, 1995, pp. 347-352. Poco más aporta VELASCO GARCÍA, Rocío: El Palacio episcopal de Córdoba: Historia y transformaciones. Tesis doctoral defendida en la Universidad de Córdoba, 2012, pp. 110-113.

${ }^{44}$ FERNÁNDEZ DE MADRID, Alonso: Silva palentina. T. II. Palencia, 1932-1942, p. 74. ALCOCER MARTÍNEZ, Mariano: Don Juan Rodríguez de Fonseca: estudio crítico-biográfico. Valladolid, 1926, p. 26, dice que reformó los dormitorios y los dotó de mobiliario y ropa.

45 Testamento 23. 
era obispo ${ }^{46}$. Aparte de que pudiera obedecer a una devoción personal y de la clara relación que presenta con su homónima sevillana -en cuya catedral debió ver Fonseca el original, durante sus años de beneficiado_- ${ }^{47}$, la pintura presenta un innegable interés como fuente de información del carácter e intereses del personaje, ya que esta virgen era una de las patronas del descubrimiento ${ }^{48}$, lo que indica la importancia que para Fonseca tuvo siempre su papel en los asuntos indianos. Pero lo que más nos interesa de esta obra como encargo artístico es el hecho de que, si bien la Virgen sigue fielmente el modelo de la sevillana ${ }^{49}$, el donante ha cambiado, pudiéndose reconocer claramente en el de la obra pacense a un Fonseca relativamente joven en el que es su primer retrato conocido, que lo representa de manera bastante fiel, si bien siguiendo aún la convención de la estatura jerárquica ${ }^{50}$. Esta obra indica pues que el interés por mostrar su imagen, que esta obedeciese directamente a la realidad y que además identificase las obras por él promovidas, mostrándose en ellas su voluntad de aparecer junto a aquellos personajes sagrados que consideraba, por devoción, más cercanos, está ya presente desde sus inicios como patrón artístico, y que en su carrera como tal no hará sino enriquecer esta imagen a la par que lo hacía con las obras que encargaba. Salvando las distancias no es muy diferente de la tabla central del retablo del trascoro de la catedral de Palencia que Fonseca encargaría unos años más tarde ${ }^{51}$

${ }^{46}$ La noticia la aporta DOSMA DELGADO, Rodrigo: Discursos patrios de la real ciudad de Badajoz. Madrid, 1601, f. 55r-v, en los siguientes términos: "44. Don Iuan Rodríguez de Fonseca obispo de Badajoz, se vee por escrituras año MCCCCXCVII en que a treinta de Iunio hizo constituciones, y año 1498 por fin de Iulio, traxo este prelado la devota imagen / de la Antigua sacada de la de Seuilla, como al pie lo dize este disticho mejor medido que el de don Gil: Pacensis populi praesul Fonseca Ioanne".

${ }^{47}$ Aparte de la devoción que siempre profesó a la Virgen, algunos personajes cercanos a Fonseca también fueron devotos de esta imagen; es el caso de su tío abuelo, el cardenal y arzobispo de Sevilla Juan de Cervantes y de la reina Isabel, que rezaba todos los sábados ante su efigie. LAGUNA PAÚL, Teresa: "Devociones reales e imagen pública en Sevilla", Anales de Historia del Arte, 23, 2013, pp. 136-137.

${ }^{48}$ La primera ciudad permanente fundada en el Nuevo Mundo fue Santa María de la Antigua del Darién, en el actual Panamá, debido a que los españoles se encomendaron a esta Virgen para que les ayudara a vencer al cacique local, prometiéndole poner su nombre a la nueva ciudad si lo conseguían. Fue también el primer lugar del Nuevo Mundo donde se construyó un templo y una de las principales devociones americanas. Sobre la devoción a esta Virgen en América ver VENCES VIDAL, Magdalena: Ecce Maria venit. La Virgen de la Antigua en Iberoamérica. México, 2013.

${ }^{49}$ La obra conservada en la catedral pacense ha sufrido diversas y profundas restauraciones en época moderna, aunque parece que reproduce de manera bastante fiel la obra tardogótica. REDONDO CANTERA, M. J.: “Juan Rodríguez...”, op. cit., p. 178.

${ }_{50}$ En este caso Fonseca se representa vestido con hábito coral episcopal de invierno.

${ }^{51}$ Fonseca recibió el obispado de Palencia en 1504, a la vez que, estando en Flandes, entraba como miembro en la cofradía de los Siete Dolores de la Virgen de Bruselas y, 
(Figuras 5 y 9), y en la que, al protagonismo de la Virgen, ahora compartido con San Juan -otra de sus devociones particulares-, se añade el del propio Fonseca, ya de un tamaño similar al de los otros dos personajes y vestido de una manera muy parecida a como aparece en la tabla de Badajoz - en ambos casos en hábito coral, más formal y solemne en este último caso-, aunque ahora añade la mitra a los pies y el báculo entre las manos, pero sin presentar todavía la majestuosidad del pontifical que sí aparece en obras posteriores, como la portada de la Pellejería (Figura 7) o su sepulcro ${ }^{52}$. El hecho de que esta pintura se colocara en un primer momento en el trascoro catedralicio ${ }^{53}$, confirma la semejanza con la obra palentina y constituye un antecedente del proyecto que Fonseca desarrollaría en esta última catedral en relación con el espacio coral y que quizá ya tenía en mente en los años de su primer obispado.

A sus dos primeras sedes regaló también varios libros de coro $^{54}$, en concreto cinco a la primera y unos treinta a la segunda ${ }^{55}$, muchos de ellos adornados con sus armas y las de los reyes. El conjunto, al menos los cordobeses, se hizo en Córdoba, entre 1502 y $1504^{56}$, figurando la fecha de 1499 en uno de los de la catedral pacense;

al mismo tiempo, debió encargar o comprar, hacia 1505 y con esta temática, el retablo de Nuestra Señora de la Compasión en Flandes. Su entrada oficial en Palencia fue precisamente el 4 de abril de 1506, día de la fiesta de los Siete Dolores de la Virgen. GRANADOS SALINAS, R. I.: "Sorrows for a devout ambassador...", op. cit. Las dos alas del tríptico, con las inscripciones, se añadieron entre 1517 y 1520 . MARTENS, Didier: Peinture flamande et goût ibérique aux XVème et XVIème siècles. Bruselas, 2010, p. 220.

52 Es de destacar como las ropas que lleva en sus diferentes retratos se adaptan a la funcionalidad de los espacios para los que se concibieron. Así en interiores catedralicios, donde el público más frecuente era el eclesiástico, Fonseca se representa con hábito coral, mientras que en zonas donde podía ser visto por un mayor número de laicos, el ornamento es el pontifical.

53 LAGUNA PAÚL, Teresa: "Catedral de Badajoz", en Extremadura: Cáceres y Badajoz. Madrid, 1995, p. 296.

${ }^{54}$ En esto parece seguir el ejemplo de su primo Alonso de Fonseca Quijada, quien había promovido la realización de libros de coro, iluminados por Juan y Pedro de Carrión, para la catedral de Ávila, al poco tiempo de acceder a su obispado, aunque al contrario de lo que hará Juan en los suyos, Alonso no dejó constancia directa de su patronazgo, al no incluir sus armas en los mencionados libros. VILLASEÑOR SEBASTIÁN, Fernando: El libro iluminado en Castilla durante la segunda mitad del siglo XV. Segovia, 2009, pp. 143-145.

${ }^{55}$ NIETO CUMPLIDO, Manuel: La miniatura en la catedral de Córdoba. Córdoba, 1973, pp. 51-65, recoge 29. LARA LARA, Francisco Javier: El canto llano en la catedral de Córdoba. Los libros corales de la misa. Granada, 2004, p. 34, habla de 31.

${ }^{56}$ LARA LARA, F. J.: El canto llano..., op. cit., pp. 35-36, recoge todas las fechas de finalización que aparecen en los libros, entre el 25 de abril de 1502 y el 26 de mayo de 1504 , en un total de ocho libros. YARZA LUACES, Joaquín: Los Reyes Católicos. Paisaje artístico de una monarquía. Madrid, 1993, p. 167, cree que no se interesaría excesivamente por ellos dada la calidad de sus ilustraciones, por debajo de lo habitual en las obras encargadas 
serían donados por lo tanto, a ambas catedrales, en tiempos de su obispado cordobés $^{57}$. De nuevo es el coro, y la actividad litúrgica que tenía lugar en este espacio, el objeto de interés del obispo, encargando los libros necesarios para que dicha actividad se desarrollara de acuerdo con los adecuados ornato y dignidad.

Junto con los libros de coro se interesó también por otros libros de uso litúrgico en sus sedes, preocupándose por la correcta adecuación del culto que en ellas se desarrollaba. Parece que pudo dar a la catedral de Palencia un salterio con grabados en $1512^{58}$, además de encargar, para el breviario que usaba el clero catedralicio burgalés, un anexo con vidas de santos locales ${ }^{59}$.

Además de estos libros donó o legó un número importante de objetos litúrgicos suntuarios, con diferencia la tipología artística más presente en sus legados testamentarios. De este modo, de la gran variedad y número de piezas citadas en su testamento -custodias, cálices, cruces-, una parte muy importante iría a sus templos más cercanos, especialmente a la catedral de Burgos, a la que ya poco antes de su muerte había donado un relicario de plata que contenía un brazo de San Vicente Ferrer ${ }^{60}$. En su testamento dejó a la catedral dos "barriles lisos con sus cobertores" 11 , y a la diócesis diversas piezas sin determinar destinadas a las parroquias pobres. Además, dejó al canónigo burgalés Bartolomé de Sedano "un coponcillo de plata con su pie y sobrecopa", además de "una casulla

por él, lo que no sería de extrañar dado el poco tiempo dedicado a cada libro, que se elaboraba en el plazo aproximado de un mes. Ver también SOLÍS RODRÍGUEZ, Carmelo y TEJADA VIZUETE, Francisco: "Libros corales de la catedral de Badajoz. Estudio y catalogación", Memorias de la Real Academia de Extremadura de las Letras y las Artes, II, 1998, pp. 326-384.

${ }^{57}$ El conjunto se habría terminado antes de fines de 1504, según NIETO CUMPLIDO, M.: La miniatura ..., op. cit., p. 33; y LARA LARA, F. J.: El canto llano..., op. cit, p. 33.

58 YARZA LUACES, J.: Los Reyes Católicos..., op. cit., p. 190.

${ }_{59}$ El encargo se lo hace a Juan Maldonado, protegido suyo a quien pudo conocer a través de Nebrija, ya que ambos fueron discípulos suyos, y con quien coincidió en la catedral burgalesa, en la que el primero fue capellán de la capilla de la Visitación. La obra, bajo el título Vitae Sanctorum brevi elegantique stylo compositae, fue publicada por los Junta en Burgos, en 1529. Ver la introducción de Spanish humanism on the verge of the picaresque: Juan Maldonado's Ludus chartarum, Pastor Bonus and Bacchanalia. Leuven, 2009, p. 4.

${ }^{60}$ A.C.B., Libro Registro 42, f. 89v, 28-3-1524. Se cita en un inventario de 1546 "el brazo de Sant Bizente del cuervo, que dio el obispo Fonseca. Está ya sin el cuerpo. Es de plata, siete marcos y seis onzas y media”. Recogido en BARRÓN GARCÍA, Aurelio: La época dorada de la platería burgalesa 1400-1600. Vol. I. Burgos, 1998, p. 192.

${ }_{61}$ Testamento 73. Se incluyeron en el inventario de 1546, "dos frascos o barriles de plata, que dio el obispo Fonseca; que pesa quinze marcos y çinco onzas", además de "un açetre de plata con su ysopo que tiene las armas de la iglesia y de Fonseca; que pesa quinze marcos y seis onzas" y "unas crismeras de plata blancas, que tiene las armas de Fonseca". BARRÓN GARCÍA, A.: La época dorada..., vol. II, op. cit., p. 293. 
de damasco blanco de Brujas con una cenefa vigarrada", "para que diga misa en el sepulcro"62. De la riqueza de las piezas de orfebrería religiosa de su cámara pueden dar una clara idea tanto el cáliz conservado actualmente en el museo de Santa Eulalia (Paredes de Nava, Palencia), con punzón de 's-Hertogenbosch y armas del obispo ${ }^{63}$, como el entregado a la entonces colegiata de Valladolid, dependiente de la diócesis palentina, con su escudo y punzón de esta última ${ }^{64}$.

Más, o al menos igual, de importante que la donación de estos objetos debió ser la de vestiduras litúrgicas, un ornamento fundamental para el desarrollo de una liturgia suntuosa, adecuada a la riqueza y monumentalidad de los espacios de sus sedes. En su testamento se describen con especial detalle los ornamentos que dejó a diferentes templos y que, por su descripción y por los restos que quedan, debían ser de excepcional calidad. En este sentido el más beneficiado sería la iglesia que finalmente acogió su sepultura, Santa María de Coca, a la que dejó importantes piezas textiles ${ }^{65}$.

A las catedrales de las que había sido obispo, con la excepción de Badajoz, donó o legó un ornamento de damasco carmesí completo a la catedral de Córdoba $^{66}$, un terno de brocado a la catedral de Palencia ${ }^{67}$, y un lujoso ornamento de plata bordado en oro, a la catedral burgalense ${ }^{68}$.

${ }^{62}$ Testamento 73 y 49 respectivamente.

${ }^{63}$ BARRÓN GARCÍA, Aurelio: "Un cáliz de 's-Hertogenbosch con armas del obispo palentino Juan Rodriguez de Fonseca en la iglesia de Paredes de Nava", en Estudios de platería: San Eloy 2013. Murcia, 2013, pp. 123-131. Cree que lo compraría en esta localidad flamenca a principios de 1505, en el mismo viaje en el que conseguiría el retablo del trascoro de la catedral de Palencia.

${ }^{64}$ BRASAS EGIDO, José Carlos: La platería vallisoletana y su difusión. Valladolid, 1980, p. 117.

${ }^{65}$ En concreto varios ternos de los que el más lujoso era uno negro con calaveras que debía usarse únicamente para las misas de réquiem que se dijeran en su memoria, la de sus familiares directos y la de los reyes católicos. Testamento 9-11. El uso de este ornamento, de varios tapices legados igualmente -Testamento 66- y un retablo, hoy perdido, que pudo tener como destino este templo y que podría ser una copia del del trascoro de Palencia, en el que aparecía retratado un obispo de cierta edad revestido de pontifical, que podría ser Fonseca, pudo suponer un intento de repetir, de forma limitada y mucho más modesta, la liturgia funeraria que había diseñado para la catedral palentina, complementada en este caso por el protagonismo de su propia sepultura. Da noticia del retablo COLLAR DE CÁCERES, Fernando: "Pintura en Segovia de 1450 a 1500", Estudios Segovianos, 97, 1998, p. 100.

66 Testamento 12.

${ }^{67}$ Esta obra había sido donada en vida. FERNÁNDEZ DE MADRID, A.: Silva palentina..., op. cit., p. 74.

${ }^{68}$ Dejó este ornamento en su testamento, pero no como legado, sino como compensación por otros bienes que había tomado de la mesa obispal. Testamento 48 . 
También en su testamento recordó a otras casas religiosas que estuvieron bajo su dirección y a las que legó algunas vestiduras litúrgicas, en concreto la abadía de Santa María de Párraces y San Isidoro de León ${ }^{69}$.

Como era habitual en él en estos legados hay una clara jerarquía, expresada en la cantidad y calidad de lo donado o legado, en función de la importancia del templo, siendo las obras más ricas para las sedes más relevantes en su carrera eclesiástica.

Otro capítulo importante en los legados testamentarios es el dedicado a tapices y otros paños suntuarios de uso monumental, tipología que sabemos era muy de su agrado y de la que se había preocupado por comprar y encargar piezas en sus estancias en Flandes. En su testamento incluye los que sin duda consideraba más importantes, "los diez paños ricos de la historia de la creación", comprados seguramente en Flandes, de los que dejó cuatro a la catedral de Palencia ${ }^{70}$, cuatro a la de Burgos ${ }^{71}$, y dos a la iglesia de Santa María de Coca, a la que además legaba otros dos con la historia del nacimiento que había heredado de su tío, el arzobispo viejo, también enterrado en este templo ${ }^{72}$. Para la catedral palentina mandó también comprar "cuatro paños buenos con la historia de la Salve Regina de valor de cuatrocientos ducados, los cuales se pongan y cuelguen en los días de Nuestra Señora e en otras fiestas solenes y pascuas para decir la memoria y salve

${ }^{69}$ Testamento 50 y 51 respectivamente. TEIJEIRA PABLOS, María Dolores: "Los legados suntuarios de Juan Rodríguez de Fonseca. El terno de San Isidoro de León”, Liño, 24, 2018 (en prensa). A Párraces dejó también en su testamento dinero para misas que debían decirse cada año - Testamento 8-. Es probable que en este caso quisiera mantener una memoria ligada al linaje familiar, ya que de esta casa habían sido también abades otros miembros de la familia; además este legado de su testamento se une a uno similar para el convento de Guisando, al que estaba también ligada la memoria del arzobispo viejo.

${ }^{70}$ A estos cuatro, hoy conservados en la catedral, se añadieron los escudos de Fonseca con posterioridad. FERNÁNDEZ DE MADRID, A.: Silva palentina ..., op. cit., p. 75. Sobre la serie de tapices ver CAHILL, Emma: "Los tapices del cardenal Thomas Wolsey y el obispo Juan Rodríguez de Fonseca: modelos morales al servicio del poder regio", en Reyes y Prelados: la creación artística en los reinos de León y Castilla. Madrid, 2014, pp. 455-468, especialmente 473-480.

${ }^{71}$ De los cuatro legados solo se conservan en la catedral dos. Sobre el proceso de venta de los dos restantes MARTÍNEZ RUIZ, María José y ZALAMA RODRÍGUEZ, Miguel Ángel: "Valoración y conservación del patrimonio: la venta de los tapices del obispo Fonseca en las catedrales de Burgos y Palencia", en Arqueología, arte y restauración: actas del IV Congreso internacional "Restaurar la memoria”. Valladolid, 2004, pp. 723-738, especialmente 731-738; y MARTÍNEZ RUIZ, María José y ZALAMA RODRÍGUEZ, Miguel Ángel: "Tapices del obispo Juan Rodríguez de Fonseca en las catedrales de Burgos y Palencia: desde la donación a nuestros días", en Alma ars. Estudios de arte e historia en homenaje al Dr. Salvador Andrés Ordax. Valladolid, 2013, pp. 281-296.

72 Testamento 66. 
que nos tenemos mandado decir", de los que ya se ha hablado y que llegaron a la catedral palentina, donde todavía se conservan, en $1529^{73}$ (Figura 10).

\section{LOS ENCARGOS PERSONALES}

Si en su papel como comitente artístico de los templos que estaban bajo su cargo Fonseca actuó con la responsabilidad propia de sus respectivos cargos, en sus encargos más personales es quizá donde, con mayor libertad, pudo aplicar su gusto e intereses más cercanos. En este sentido, como en las obras "oficiales", el obispo quiso rodearse de espacios y objetos de la más alta calidad, de las tipologías propias de un miembro importante de la nobleza y el alto clero y de las formas artísticas más actuales de su momento y más adecuadas a la consecución de sus fines. De este modo estos encargos más personales están también marcados por la adecuación a los conceptos de ornato - belleza, riqueza, monumentalidad, suntuosidad, magnificencia-, dignidad-adecuación a los requerimientos de un gran señor: palacio, hospital y capilla funeraria- y memoria - presencia de la persona y el linaje en la obra a través de la heráldica-, además de por la evolución del modelo flamenco al renacentista a lo largo de su trayectoria como comitente artístico.

En este sentido Juan Rodríguez de Fonseca mandó construir para sí un gran palacio - dignidad-, y lo hizo en el solar familiar, en Toro-memoria-, a pesar de que sus obligaciones profesionales, tanto religiosas como políticas, debieron dejarle poco tiempo para residir en él. De este palacio, que habría iniciado al tiempo de ser nombrado obispo de Burgos, no se conservan más que restos fragmentarios, aunque debía ser una edificación muy lujosa y monumental, en la más pura tradición tardogótica, construido por Martín de Bruselas, arquitecto que Fonseca habría traído de Flandes y que trabajaría en varias obras castellanas, entre ellas la catedral de Palencia ${ }^{74}$. No parece que participara de manera directa en la construcción del castillo de Coca, fortaleza familiar realizada en su conjunto por

${ }^{73}$ Testamento 33 .

${ }^{74}$ En 1513 Maestre Martín encargó piedra para este palacio. VASALLO TORANZO, Luis: "El arquitecto Maestre Martín”, en El arte español en épocas de transición. León, 1992, p. 346. Maestre Martín habría llegado a España con Fonseca en 1505, tras uno de sus viajes a Flandes. Aparece documentado desde 1512 en varias de las más importantes obras arquitectónicas castellanas, como la capilla Real de Granada y las catedrales de Sevilla, Salamanca y Palencia, siempre con arquitectos del entorno del obispo, como Juan Gil de Hontañón, Juan de Ruesga o Francisco de Colonia. El palacio parece haber sido una obra fundamentalmente gótica, aunque quizá con ornamentación clasicista. VASALLO TORANZO, Luis: Arquitectura en Toro (1500-1650). Zamora, 1994, pp. 240-242. 
sus hermanos Alonso y Antonio, aunque la presencia de Juan de Ruesga y de alarifes sevillanos podría deberse al intermedio de Juan ${ }^{75}$.

Su gran empresa personal sería el hospital de la Asunción y los Santos Juanes de Toro, por la que comenzó a interesarse hacia 1516-1517, retomando un hospital ya fundado previamente pero apenas iniciado, con la intención de unificar en el los restantes hospitales de Toro, pretendiendo que fuera un gran hospital, moderno y eficaz, quizá siguiendo el ejemplo de los emprendidos por los Reyes Católicos ${ }^{76}$, que tendrá su continuidad en su interés por los hospitales de sus últimas sedes. En principio la obra tendría planta de cruz, aunque solo llegaron a construirse dos alas y un patio de los que se conserva este último, la escalera y la capilla, todo con las armas del obispo ${ }^{77}$.

De la lectura de su testamento, especialmente el codicilo, se deduce la gran riqueza que, en piezas de orfebrería, tanto religiosa como civil, tenía su cámara; algunas, según se cita "con muchos escudos de su señoría". La mayoría de estas piezas estaban destinadas a sus familiares más directos: su hermano Antonio -heredero universal-, su sobrino Juan, su sobrina Mayor y sus servidores más cercanos. Muebles, textiles lujosos, objetos de orfebrería tanto civil como religiosa se citan en su testamento, aunque algún otro de gran interés, como su libro de horas, de origen flamenco y conservado actualmente en el seminario de San Carlos de Zaragoza, no se menciona ${ }^{78}$; a diferencia de otros obispos no parece haber tenido un gran interés por la conservación de su biblioteca, de la que deja a su sobrino Juan "de que sus libros tome los que mejor le paresciese"79.

Como otros nobles de su momento quiso también asegurar la permanencia de la memoria de su nombre y linaje a través de su enterramiento. La elección de lugar para sepultarse no parece haber sido temprana. Como otros prelados pudo haber querido enterrarse en alguna de sus catedrales; de hecho se ha hablado en alguna ocasión de su interés en ser sepultado en la cripta de San Antolín de la

${ }^{75}$ VASALLO TORANZO, Luis: "El castillo de Coca y los Fonseca. Nuevas aportaciones y consideraciones sobre su arquitectura", Anales de Historia del Arte, 24, 2014, pp. 61-85.

${ }^{76}$ VASALLO TORANZO, L.: Arquitectura en Toro..., op. cit., pp. 162-168.

${ }^{77}$ El hospital fue el principal beneficiario, después de su hermano Antonio, de su legado, dejándole en su testamento dinero y rentas para su construcción y funcionamiento, además de ropa y plata y del encargo de varias imágenes de sus devociones personales -la Virgen y los santos Juanes- para la fachada. Testamento 13-22. En este obliga también a los esclavos que libera a trabajar dos años en esta obra, lo que indica claramente que estaría lejos de estar finalizada a su muerte.

78 YARZA LUACES, J.: Los Reyes Católicos..., op. cit., p. 379.

${ }^{79}$ Codicilo del Testamento, 23-12-1523. 
catedral palentina ${ }^{80}$, o en la catedral de $\operatorname{Burgos}^{81}$, aunque finalmente, como queda claro en su testamento, se decidió por el panteón familiar en la iglesia de Santa María de Coca, centro del mayorazgo creado por su tío, el arzobispo viejo, y templo edificado prácticamente a expensas suyas y de su hermano Antonio ${ }^{82}$, y donde ya descansaban su tío, los padres de Juan y su hermano Alonso con su madre, añadiéndose posteriormente la sepultura, más sencilla, de Antonio.

Para el panteón familiar, Juan y su hermano Antonio encargaron los sepulcros monumentales de los personajes citados a Bartolomé Ordóñez ${ }^{83}$, aprovechando los viajes a Italia de Antonio en el ejercicio de su servicio a la corona -entre ellos el encargo de los sepulcros de Felipe y Juana y el de los Reyes Católicos, cuya gestión había encargado el rey Fernando a los hermanos Antonio y Juan, junto con Juan Velázquez de Cuéllar en 1513-84. La muerte de Ordóñez truncó este proyecto al dejar los sepulcros inacabados, pasando a otros talleres

${ }^{80}$ HOYOS ALONSO, J.: “Juan Rodríguez...”, op. cit. En realidad lo que expresa el documento citado en este artículo es el deseo del obispo de controlar el uso funerario de la cripta, estableciendo que solo pudieran enterrarse en ella quienes el mismo decidiera.

${ }^{81}$ En 1524, al regalar el relicario de San Vicente mencionado anteriormente, se destina éste a la capilla donde se sepulte el obispo, lo que parece indicar claramente que en este momento no había descartado la posibilidad de enterrarse en su última sede. Esta noticia coincidiría con la contenida en las Medidas del Romano de Diego de Sagredo, donde Tampeso aparece dibujando una sepultura para el propio Fonseca, proyecto aparentemente monumental, ya que Picardo cree que parece más un retablo que un sepulcro. DÍAZ DEL CORRAL, Rosario: "Muerte y humanismo: la tumba del cardenal Pedro González de Mendoza", Academia, 64, 1987, pp. 212-213. Quizá hubiera habido un cambio de opinión en marzo de este año, cuando Fonseca estuvo a las puertas de la muerte y había hecho un primer testamento, "culpándose de su mal vivir y haber llevado a las iglesias que a cargo había tenido cosas fuera de razón". "Y al tiempo de le administrar el sacramento, dicen se ató una soga al pescueço y como malo recibió el sacramento con mucho arrepentimiento de sus culpas”. RODRÍGUEZ VILLA, A.: El Emperador..., op. cit., p. 152. Quizá la creencia en una muerte inminente le llevó a plantearse el enterramiento, al menos temporal, en la catedral burgalesa. Incluso en su testamento, aunque pide claramente ser enterrado en la iglesia de Coca, no descarta enteramente ser "depositado" en otro lugar. Testamento 2.

${ }^{82}$ MORENO ALCALDE, María: "Los Fonseca y la iglesia de Santa María de Coca", Anales de Historia del Arte, 2, 1990, pp. 57-77.

${ }^{83}$ MIGLIACCIO, Luciano: "Los sepulcros de la familia Fonseca en la iglesia de Santa María la mayor en Coca (Segovia)”, en SAGARRA GAMAZO, A. (ed.): Juan Rodríguez de Fonseca: su imagen..., op. cit., pp. 207-219.

84 VASALlO TORANZO, L.: "El castillo de Coca y los Fonseca...", op. cit., p. 85, dice que Maestre Martín dio en 1514 ciertas "muestras" para el sepulcro de los Reyes Católicos que se hacía en Génova. 
de escultores italianos que simplificaron el encargo, perdiéndose la monumentalidad del diseño original ${ }^{85}$.

En su testamento estableció ser enterrado a la izquierda del altar mayor, frente al sepulcro de su tío y si bien determinó con todo lujo de detalles cómo debía ir vestido y qué piezas debían acompañar a su cuerpo -todo ello suntuoso y adecuado a la solemnidad del enterramiento de un obispo ("vestido en hábito pontifical, como la dinidad episcopal pertenece")-, se describen como relativamente pobres, con adjetivos como "de muy poco valor", "todo muy pequeño", "de plata muy pobre", en un intento de rodear el momento de su muerte de una humildad y sencillez que nunca le interesaron en vida ${ }^{86}$.

Esta última obra muestra el final de una clara evolución en su gusto estético, pero también, muy probablemente, la influencia de su entorno más inmediato, especialmente de los reyes Isabel y Fernando, con los que mantuvo una relación muy estrecha y que estuvieron presentes en muchas de las obras patrocinadas por el obispo, en el protagonismo otorgado a las armas regias, superior incluso al del propio comitente. En este sentido Juan Rodríguez de Fonseca parte del uso del modelo artístico flamenco, que conoció de primera mano en sus viajes a Flandes en la década de los 90 y primeros años del siglo $\mathrm{XVI}^{87}$, y que puede

${ }^{85}$ A la muerte de Ordóñez el sepulcro de don Juan tenía el yacente desbastado, empezados los arcos, solo esbozadas dos piezas del entablamento, con dos columnas, un capitel y dos pedestales. También tenía empezadas dos piezas del entablamento y dos de la base del sarcófago, aparte de tener terminada, y en su caja, una imagen de la Virgen con el Niño y San Juan Bautista - de nuevo las devociones particulares del obispo- que hoy se conserva en la catedral de Zamora. REDONDO CANTERA, M. J.: "Juan Rodríguez de Fonseca...", op. cit., pp. 212-213. Migliaccio deduce que en el taller de Ordóñez se terminarían los sepulcros de don Juan y sus padres y el resto en el de Aprile da Carona. Rossi da Fiésole, que se hizo cargo del taller de Ordóñez a la muerte de éste, haría el frente del sarcófago del obispo, con los angelotes sosteniendo su escudo; el yacente, que solo estaría desbastado a la muerte de Ordóñez sería una copia del de su tío, que ya estaba acabado. MIGLIACCIO, L.: "Los sepulcros....", op. cit. Las obras no se enviaron a España hasta 1533 debido al retraso en el pago, a pesar de que Fonseca, en su testamento, establecía que se pagase a un mercader barcelonés "lo que se le debe de mi sepultura", supuestamente por el trabajo de este en el traslado de las piezas. Testamento 62. Parece que, en realidad, fue Juan de Fonseca, hijo de Antonio, el que se encargó de traerlos a la muerte de su padre, en 1533, aunque no se instalaron en Coca hasta 1538. Hasta entonces habían estado en Cartagena, donde se guardaron un tiempo en un almacén derruido, habiéndose dañado el báculo de Juan al caerse la cubierta. RODRÍGUEZ MARTÍNEZ, Felipe: "Nuevas aportaciones al estudio de los sepulcros de los Fonseca”, Estudios Segovianos, 88, 1991, p. 73.

86 Testamento 2.

${ }^{87} \mathrm{Su}$ carrera diplomática se había iniciado en 1488, cuando viajó a Francia para negociar la devolución de Rosellón y Cerdaña y continuó con diversas misiones en Flandes, desde 1491 cuando viajó allí por primera vez para iniciar las negociaciones con Maximiliano de Austria para la doble boda de los hijos de éste -Margarita y Felipe- con el 
verse claramente en objetos de uso personal como su Libro de horas, en su perdido palacio de Toro, en el hospital promovido por él en la misma localidad, pero también en las obras encargadas en estas fechas para la catedral palentina, donde contó con los mejores artistas de tradición flamenca que trabajaban entonces en Castilla, como los arquitectos Gil de Hontañón o Juan de Ruesga y los pintores Juan de Flandes o Jan Joest de Calcar. A partir de la década de los diez del siglo XVI, y ya en Burgos, va conociendo el modelo italiano, primero a través de su versión más decorativa -que puede verse en la puerta de la Pellejería de la catedral burgalesa o en la escalera de bajada a la cripta de San Antolín de la sede palentina $-^{88}$, modelo renacentista ya plenamente desarrollado en sus últimos encargos -la escalera dorada de la catedral de Burgos, obra de Diego de Siloé y su sepulcro y el de sus familiares, encargados a Bartolomé Ordóñez para el panteón familiar de Santa María de Coca-, en una evolución muy semejante a la que vive el arte castellano del momento. En esta evolución tendría una influencia significativa su cercanía a su hermano Antonio, quien conocería de primera mano el modelo renacentista gracias a sus campañas en Italia.

En este sentido, y dada la fundamental influencia tanto de los monarcas como de Antonio de Fonseca a lo largo de toda la vida de Juan, es difícil establecer hasta dónde llega el gusto personal del obispo y su conocimiento directo de ambos modelos artísticos y hasta dónde se trata únicamente del deseo de emular, homenajear o simplemente seguir el ejemplo de estas y otras figuras. Así el tríptico flamenco de los siete dolores de la Virgen del trascoro palentino ligaría su figura a la de Juana y Felipe, como miembros - como el mismo Fonseca- de la cofradía bruselense homónima, la utilización de la ornamentación italiana en la escalera de la cripta palentina lo vincularía a la antigüedad de la figura de San Antolín y del primer templo de la sede ${ }^{89}$, y los sepulcros de Coca a las tumbas de la capilla Real de Granada, lo que reforzaría su relación con los monarcas, además de vincularlo más directamente con su hermano y la presencia de la familia en Italia. Es evidente que estas cuestiones tuvieron un peso significativo en la elección de artistas y de modelos, aunque pudieron funcionar también en el sentido contrario, proporcionando don Juan artistas para otras obras relacionadas con su figura, bien entre sus sedes -sería el caso ya mencionado de Francisco de Colonia entre Burgos y Palencia- bien en obras patrocinadas por otros miembros de su familia, como sucede en el caso de la posible participación de Juan de Ruesga

príncipe Juan y la infanta Juana. SAGARRA GAMAZO, A.: Juan Rodríguez de Fonseca: un toresano..., op. cit.

${ }^{88}$ Vinculada a la intervención de Francisco de Colonia en la obra burgalesa, Redondo Cantera cree posible también su presencia en la palentina. Ver nota 20.

${ }^{89}$ REDONDO CANTERA, M. J.: “Juan Rodríguez de Fonseca...”, op. cit., p. 191. 
en el castillo de Coca, también mencionada, o en el probable encargo de la iglesia de Santa María de Coca a Gil de Hontañón ${ }^{90}$.

Más allá de la exitosa elección de artistas para las obras que encargó, Fonseca se preocupó muy directamente de todas ellas, intentando siempre procurar que tuvieran la más alta calidad artística y dotarlas de un contenido simbólico en función de sus intereses y necesidades, sin olvidar el deseo de garantizar su presencia permanente en las catedrales de las que fue obispo a través de la repetición de sus escudos. Presencia personal pero también, consciente de la relevancia de su linaje y de su cargo, familiar e institucional, contribuyendo a reforzar la importancia de la figura del prelado en el templo catedralicio frente al tradicional control de los cabildos. Sus actuaciones en el entorno de los espacios corales de sus sedes, separándolos y diferenciándolos del ámbito del altar y subrayando en ellos el protagonismo del obispo, a través del uso de su propia imagen, se enmarca tanto en la política religiosa reformista de los Reyes Católicos como en la general de la iglesia que culminará en Trento, de donde saldrá claramente reforzada la institución episcopal. Es por todo ello uno de los comitentes artísticos más importantes, interesantes y significativos de su momento, mostrando especialmente, en las obras encargadas para sus catedrales, la riqueza y complejidad de su patronazgo.

Fecha de recepción: 25 de mayo de 2016

Fecha de aceptación: 4 de enero de 2017

${ }^{90}$ MORENO ALCAIDE, M.: "Los Fonseca y la iglesia...”, op. cit. 


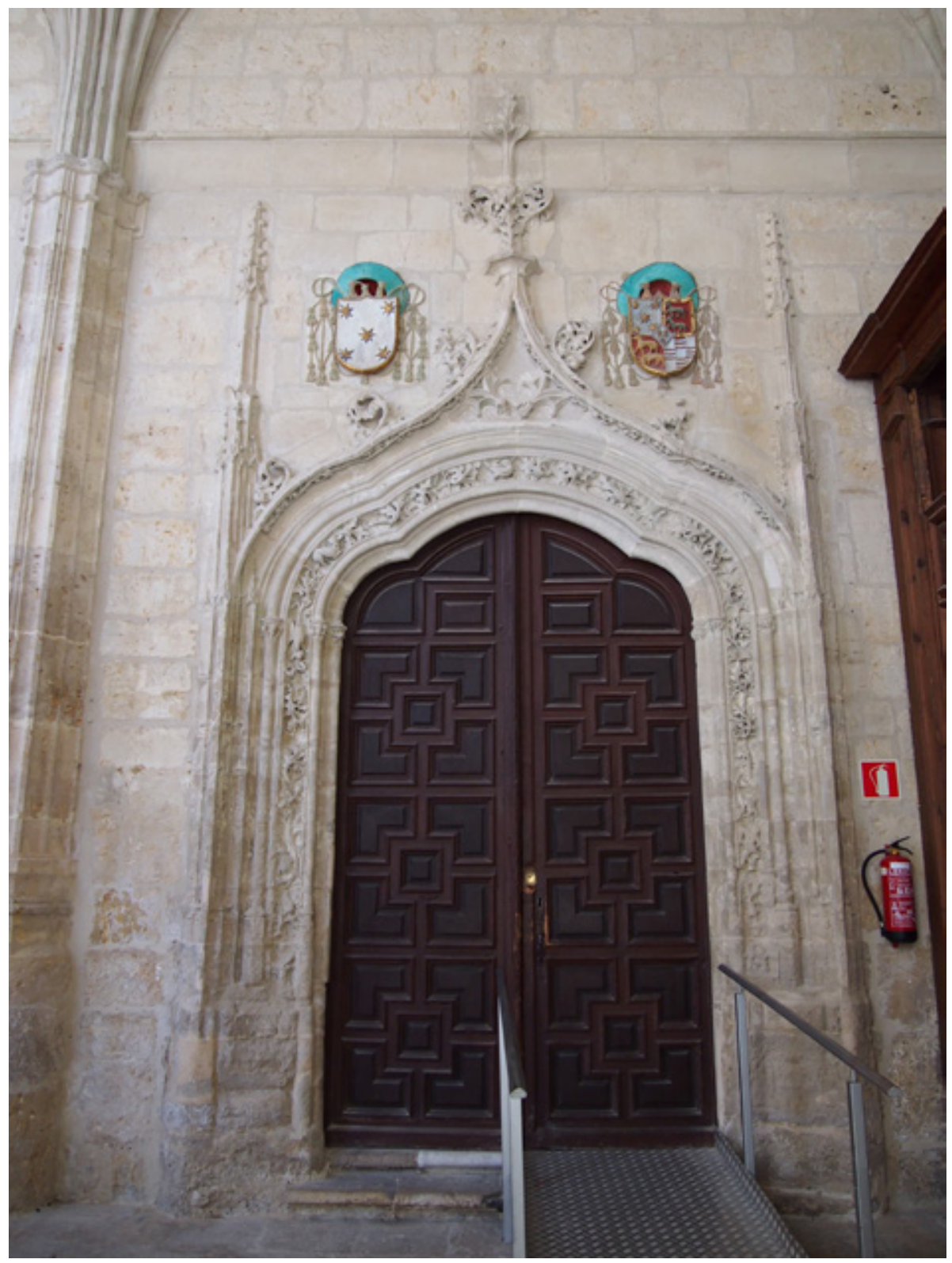

Figura 1. Portada, hacia 1505, sala capitular, catedral de Palencia. Foto: María Dolores Teijeira Pablos. 


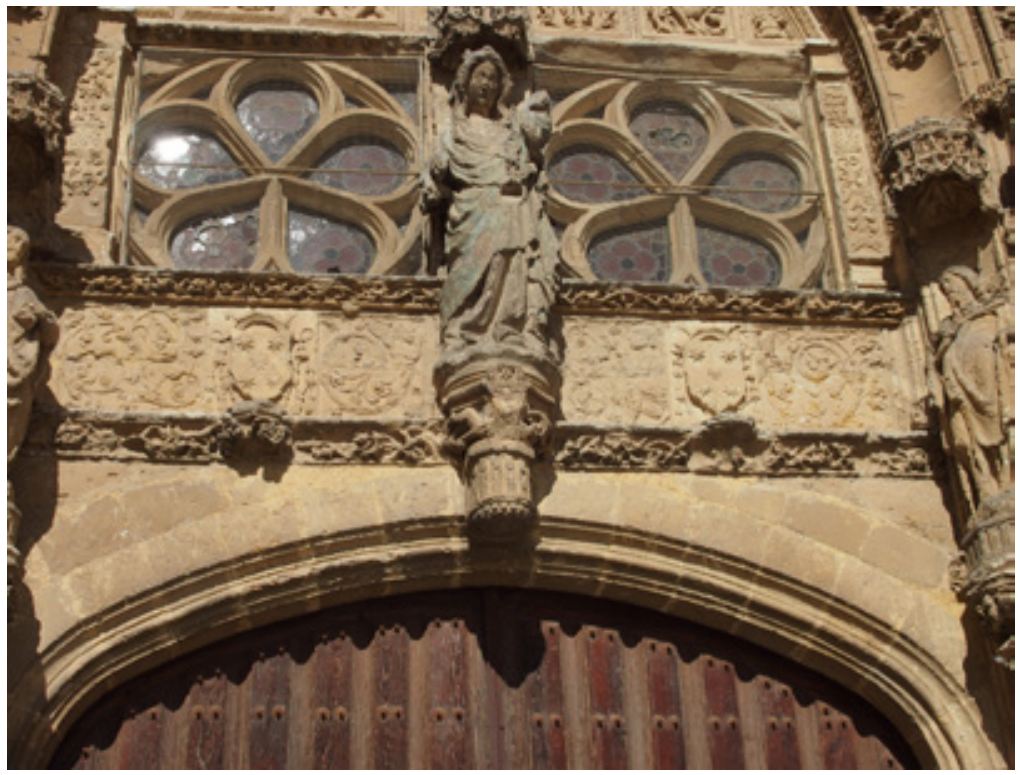

Figura 2. Escudos de Fonseca, puerta del Obispo, catedral de Palencia. Foto: María Dolores Teijeira Pablos.

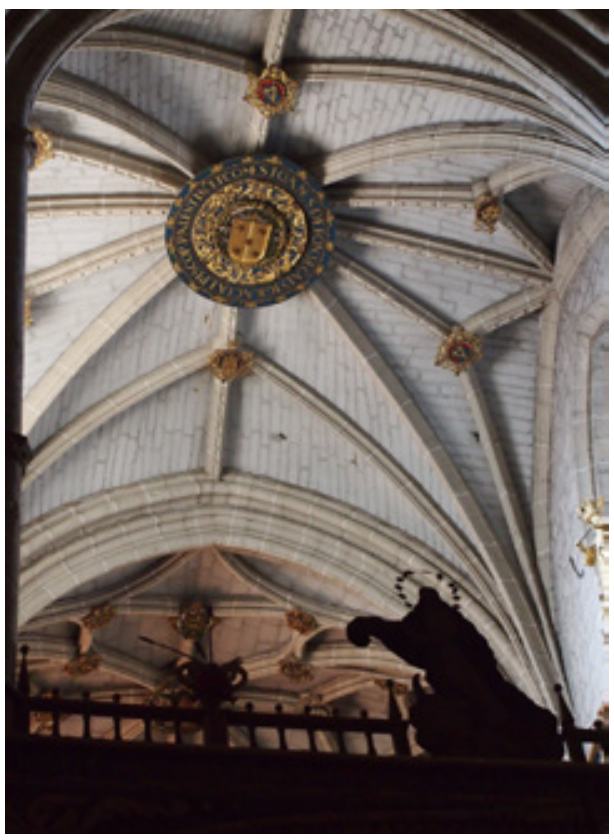

Figura 3. Escudo de Fonseca, clave de la primera bóveda del coro, catedral de Palencia. Foto: María Dolores Teijeira Pablos. 


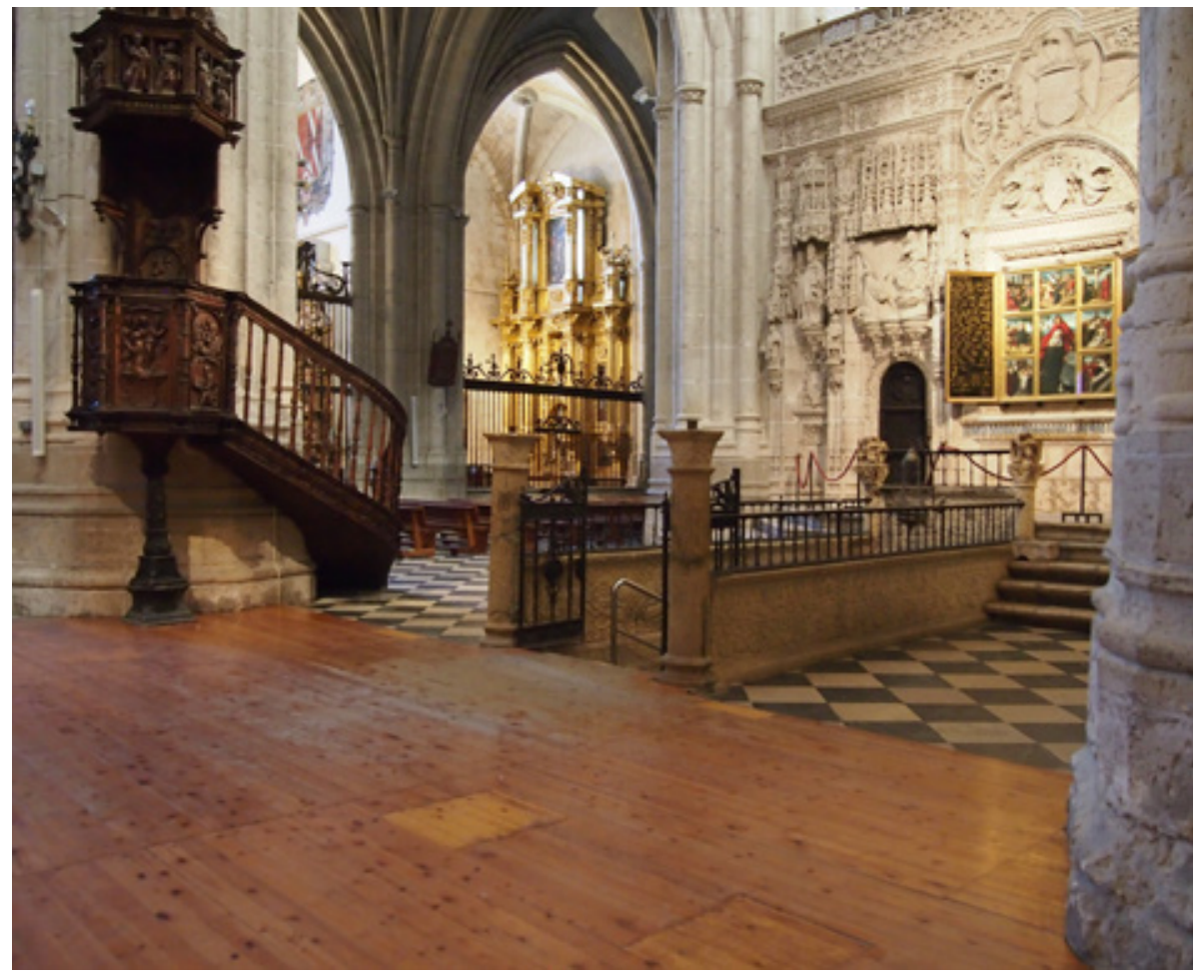

Figura 4. Trascoro, catedral de Palencia. Foto: María Dolores Teijeira Pablos. 


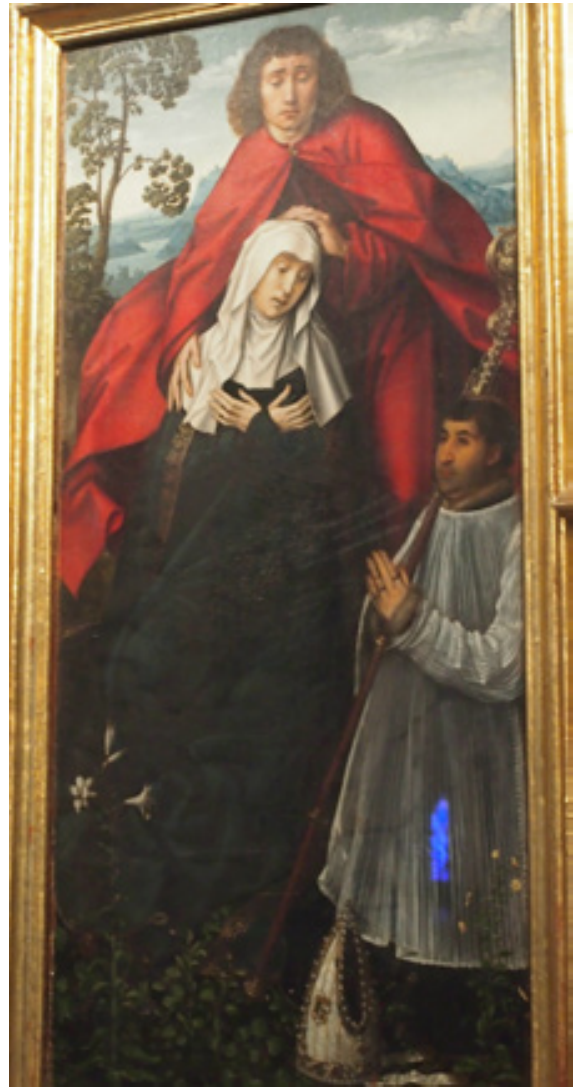

Figura 5. Fonseca como orante, retablo del trascoro, catedral de Palencia. Foto: María Dolores Teijeira Pablos.

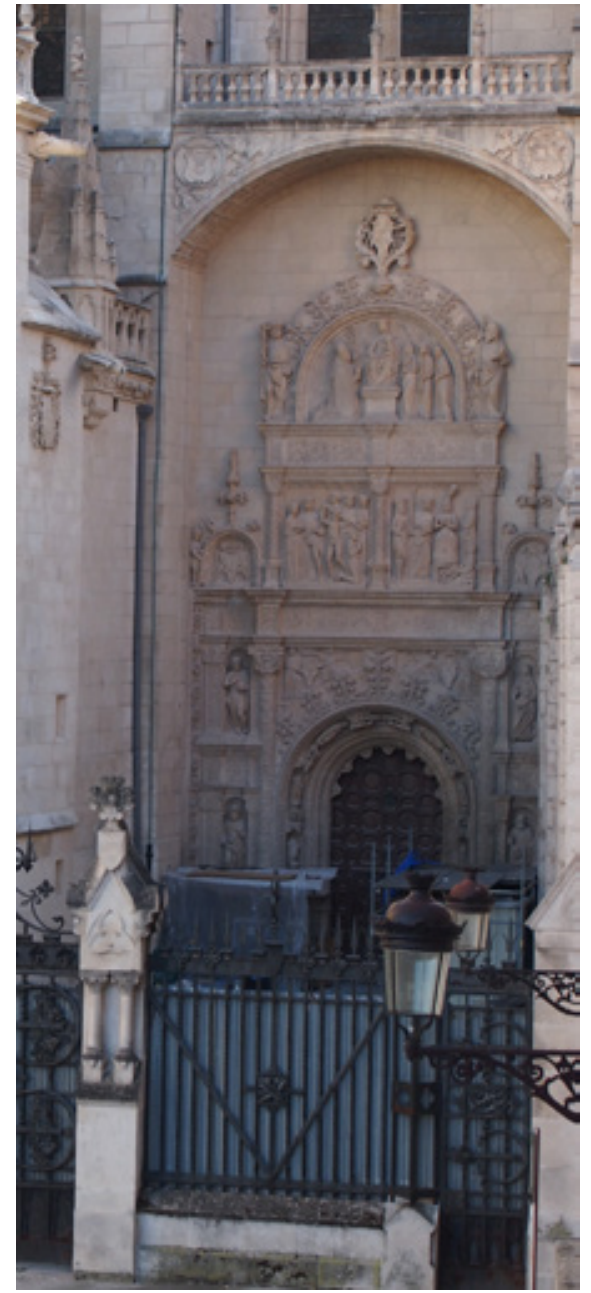

Figura 6. Puerta de la Pellejería, hacia 1516, catedral de Burgos. Foto: María Dolores Teijeira Pablos. 


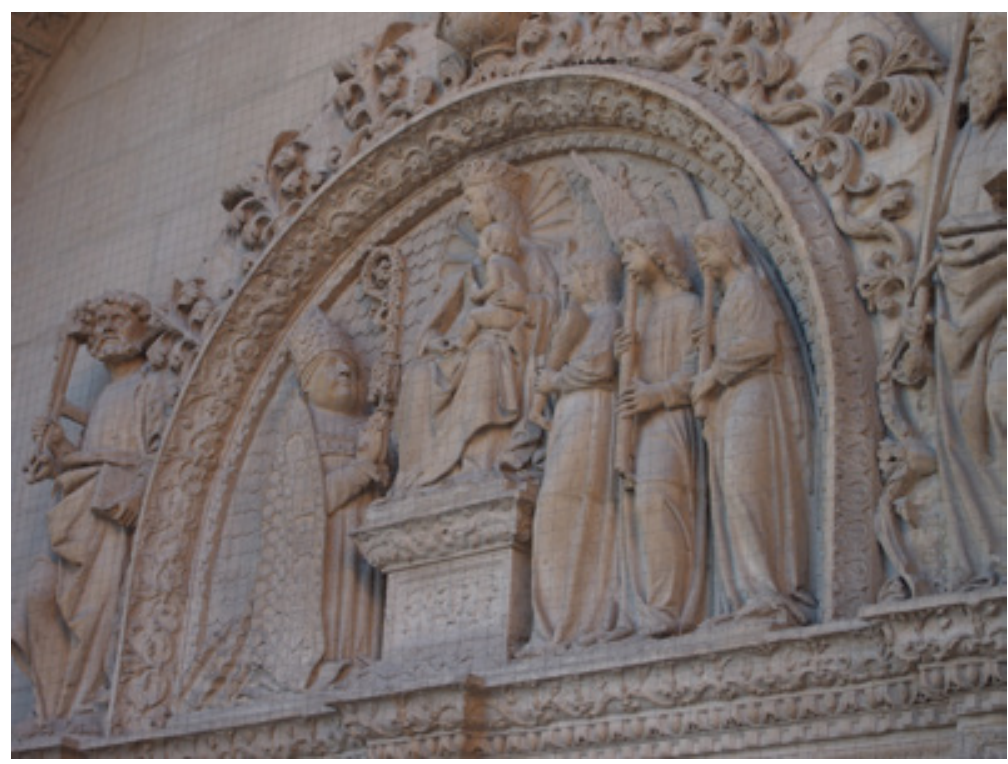

Figura 7. Fonseca orante ante la Virgen, hacia 1516, puerta de la Pellejería, catedral de Burgos. Foto: María Dolores Teijeira Pablos.

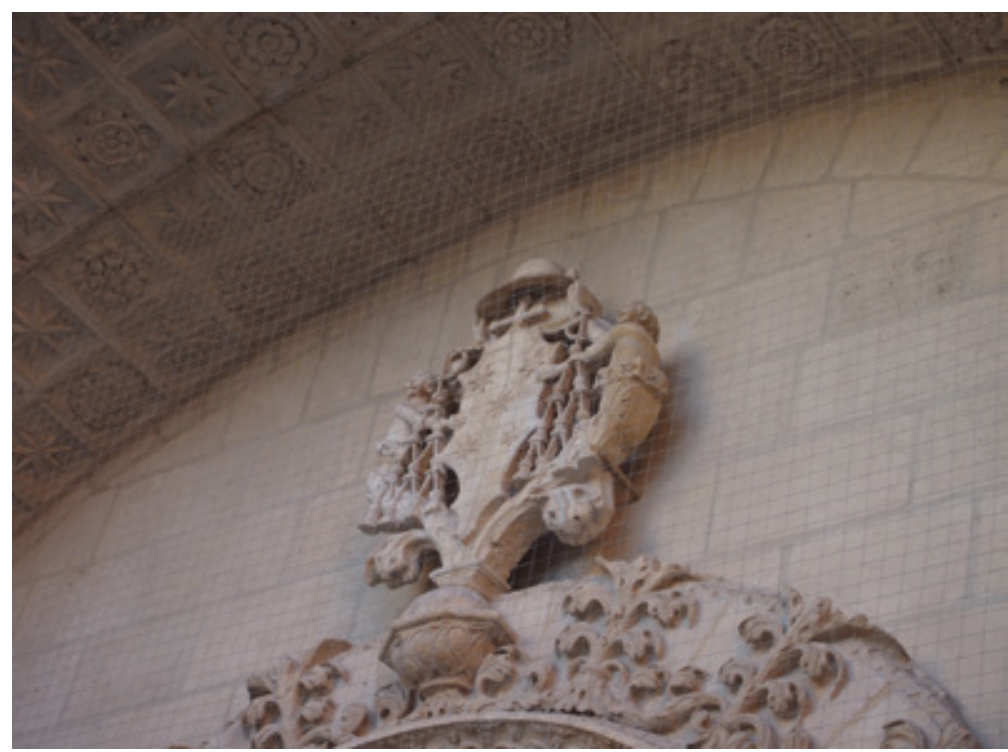

Figura 8. Escudo de Fonseca, hacia 1516, puerta de la Pellejería, catedral de Burgos. Foto: María Dolores Teijeira Pablos. 


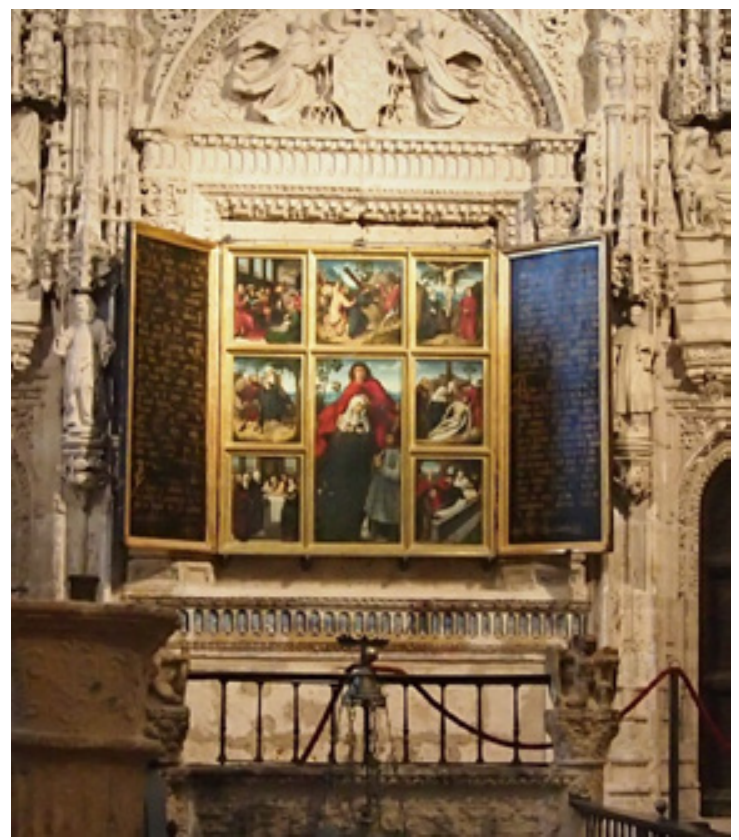

Figura 9. Jan Joest de Calcar, Retablo del trascoro, hacia 1505 , catedral de Palencia. Foto: María Dolores Teijeira Pablos.

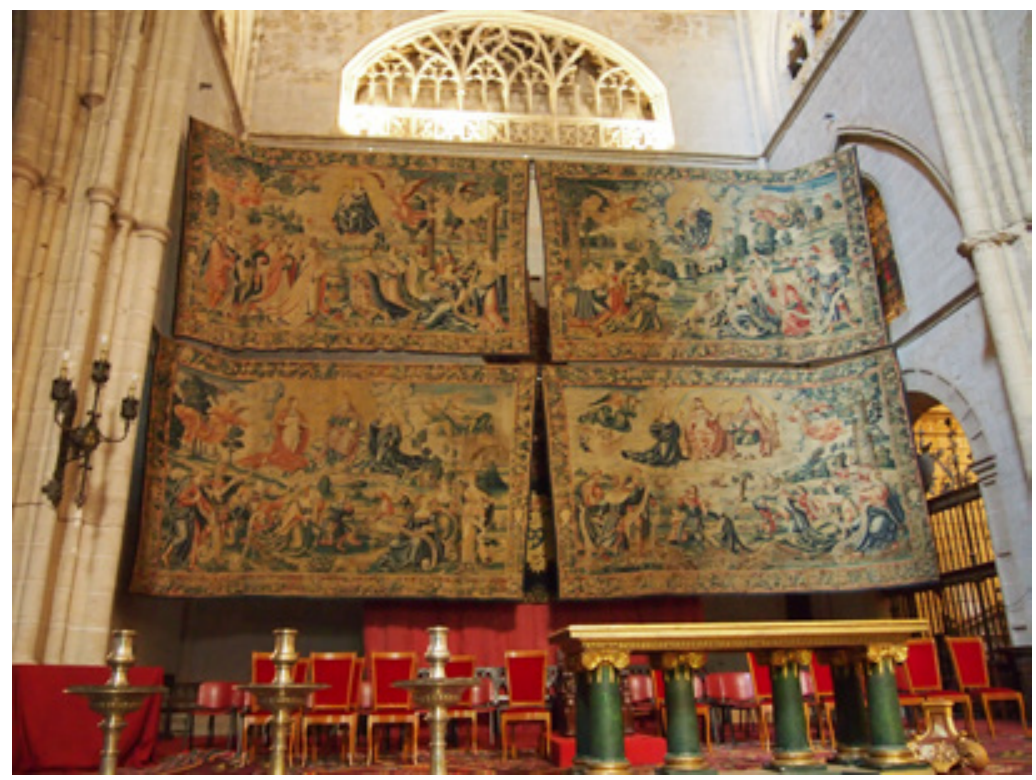

Figura 10. Tapices de la Salve, antes de 1529, catedral de Palencia. Foto: María Dolores Teijeira Pablos. 